\title{
Neural Representation of a Target Auditory Memory in a Cortico-Basal Ganglia Pathway
}

\author{
Jennifer M. Achiro ${ }^{1}$ and Sarah W. Bottjer ${ }^{2}$ \\ ${ }^{1}$ Neuroscience Graduate Program and ${ }^{2}$ Section of Neurobiology, University of Southern California, Los Angeles, California 90089
}

Vocal learning in songbirds, like speech acquisition in humans, entails a period of sensorimotor integration during which vocalizations are evaluated via auditory feedback and progressively refined to achieve an imitation of memorized vocal sounds. This process requires the brain to compare feedback of current vocal behavior to a memory of target vocal sounds. We report the discovery of two distinct populations of neurons in a cortico-basal ganglia circuit of juvenile songbirds (zebra finches, Taeniopygia guttata) during vocal learning: (1) one in which neurons are selectively tuned to memorized sounds and (2) another in which neurons are selectively tuned to selfproduced vocalizations. These results suggest that neurons tuned to learned vocal sounds encode a memory of those target sounds, whereas neurons tuned to self-produced vocalizations encode a representation of current vocal sounds. The presence of neurons tuned to memorized sounds is limited to early stages of sensorimotor integration: after learning, the incidence of neurons encoding memorized vocal sounds was greatly diminished. In contrast to this circuit, neurons known to drive vocal behavior through a parallel cortico-basal ganglia pathway show little selective tuning until late in learning. One interpretation of these data is that representations of current and target vocal sounds in the shell circuit are used to compare ongoing patterns of vocal feedback to memorized sounds, whereas the parallel core circuit has a motor-related role in learning. Such a functional subdivision is similar to mammalian cortico-basal ganglia pathways in which associative-limbic circuits mediate goal-directed responses, whereas sensorimotor circuits support motor aspects of learning.

\section{Introduction}

Both humans and songbirds display the rare trait of vocal learning; juveniles hear and memorize vocal sounds of adult "tutors" during a sensitive period of development and then translate the neural memory of those sounds into a motor program (Doupe and Kuhl, 1999). The existence of a stable memory of tutor sounds in songbirds was first demonstrated behaviorally by seminal work in the 1950s (Marler, 1956; Thorpe, 1958; Marler, 1970). Acquiring a neural representation of tutor song is the first essential step in the process of vocal learning, and, once formed, this memory guides sensorimotor integration as each bird learns to imitate its tutor's song by vocalizing and using auditory feedback to compare its incipient vocalizations to that tutor memory (Konishi, 1965).

Parallel cortico-basal ganglia loops in mammals process distinct but related aspects of sequential motor and reward-based learning (Hikosaka et al., 1999; O’Doherty et al., 2004; Tanaka et al., 2004; Yin et al., 2009; Thorn et al., 2010). In songbirds, the cortical region LMAN (lateral magnocellular nucleus of the anterior nidopallium) is required for vocal learning (Bottjer et al.,

Received Feb. 15, 2013; revised Aug. 5, 2013; accepted Aug. 5, 2013.

Author contributions: J.M.A. and S.W.B. designed research; J.M.A. performed research; J.M.A. contributed unpublished reagents/analytic tools; J.M.A. analyzed data; J.M.A. and S.W.B. wrote the paper.

This work was supported by National Institute of Neurological Disorders and Stroke Grant NS 037547 and Training Fellowship NS 073323 and National Institute on Deafness and Other Communication Disorders Training Fellowship DC 009975. We thank Vanessa Miller-Sims for RA/Ai tissue and Tansu Celikel for technical advice.

The author(s) declare(s) no competing financial interests.

Correspondence should be addressed to Jennifer McGrady Achiro, 3641 Watt Way, HNB 218, Los Angeles, CA 90089-2520. E-mail:mcgrady@usc.edu.

DOI:10.1523/JNEUROSCI.0710-13.2013

Copyright $\odot 2013$ the authors $\quad 0270-6474 / 13 / 3314475-14 \$ 15.00 / 0$
1984; Scharff and Nottebohm, 1991; Aronov et al., 2008). LMAN is composed of two subregions, a core and a surrounding shell, whose pathways make parallel connections to form recurrent loops through the basal ganglia and through other cortical regions (Bottjer, 2004; Fig. 1A). Neurons in LMAN core project to vocal motor cortex and drive motor variability that is characteristic of babbling in juvenile birds to facilitate trial-and-error learning (Olveczky et al., 2005; Warren et al., 2011; Ravbar et al., 2012). However, strong evidence for a neural representation unique to tutor song in this circuit has been lacking. Neurons in the shell region of LMAN project to an adjacent area of motor cortex necessary for accurate temporal sequencing and copying of tutor syllables but not for normal vocal production (Johnson et al., 1995; Iyengar et al., 1999; Bottjer et al., 2000; Bottjer and Altenau, 2010). Furthermore, the shell pathway receives a strong

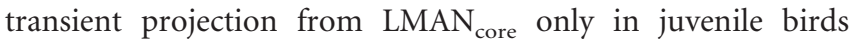
(Miller-Sims and Bottjer, 2012; Fig. 1B), indicating that core neurons convey efference copy to LMAN $_{\text {shell }}$ circuitry as birds are engaged in vocal learning. This pattern of results suggests that neurons in $\mathrm{LMAN}_{\text {shell }}$ may contribute to evaluating whether current vocal behavior matches the tutor song memory.

Neurons in $\mathrm{LMAN}_{\text {core }}$ develop auditory selectivity to each bird's own song during vocal learning, but individual core neurons in young juveniles respond to both the bird's own song and the tutor song even when they have been manipulated to be acoustically dissimilar (Solis and Doupe, 1997, 1999, 2000; Yazaki-Sugiyama and Mooney, 2004). We predicted that, in contrast to $\mathrm{LMAN}_{\text {core }}$, $\mathrm{LMAN}_{\text {shell }}$ in young birds should receive information regarding learned tutor sounds and hence contain neurons that respond selectively to the tutor song. In accord with 
A
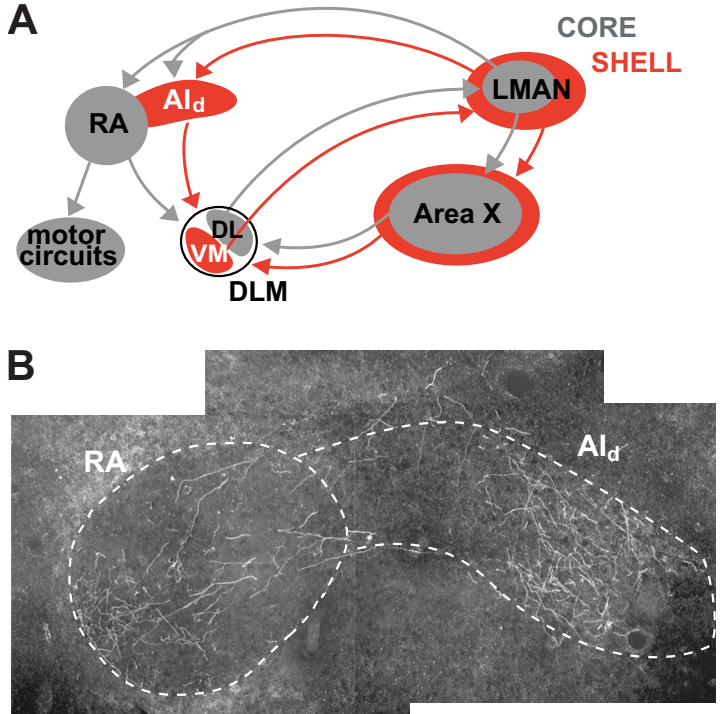

Juvenile

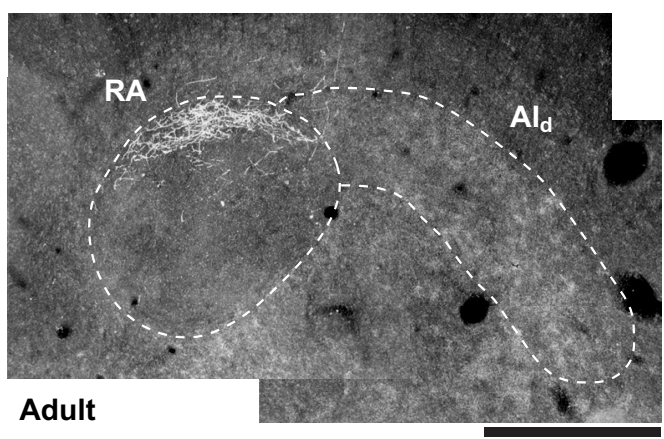

Figure 1. Parallel cortico-basal ganglia pathways in songbirds. $A$, Parallel circuits are formed by the axonal connections of core (gray) and shell (red) regions of LMAN. These parallel projections form recurrent loops through both the basal ganglia (Area X, a nucleus containing both striatal and pallidal neurons) and through other cortical regions: RA (robust nucleus of arcopallium) and $\mathrm{Al}_{d}$ (dorsal intermediate arcopallium), which are located in the analog of mammalian motor cortex. $\mathrm{Al}_{\mathrm{d}}$ was referred to as Ad (dorsal arcopallium) in previous papers from our laboratory, but we have changed the terminology here to conform to the nomenclature suggested by Reiner et al. (2004). Core and shell regions of LMAN receive input from separate subgroups of neurons in the thalamic nucleus DLM (dorsolateral medial thalamus; VM, ventromedial; DL, dorsolateral). $\boldsymbol{B}$, Anterograde label in coronal sections of $\mathrm{RA}$ and $\mathrm{Al}_{\mathrm{d}}$ after iontophoretic injections of biotinylated dextran amine into LMAN $_{\text {core }}$. Individual core neurons send axons exclusively into RA in adult birds but send numerous collateral branches into $\mathrm{Al}_{d}$ in juvenile ( $35 \mathrm{dph}$ ) birds (Miller-Sims and Bottjer, 2012) (dorsal is up, medial is left; scale bar, $0.5 \mathrm{~mm}$ ). Thus, LMAN $_{\text {core }}$ neurons make a robust transient projection into the shell pathway during sensorimotor integration that is completely gone by adulthood.

this prediction, we found that $\mathrm{LMAN}_{\text {shell }}$ contains distinct populations of neurons that encode either the tutor song or selfproduced vocal babbling in birds in early stages of sensorimotor integration. In adult birds that have completed the process of vocal learning, the neural representation of each bird's own song is strengthened as the representation of the tutor song is diminished, indicating that these neuronal populations are specialized for the period of vocal learning.

\section{Materials and Methods}

Subjects. All procedures were performed in accordance with protocols approved by the University of Southern California Animal Care and Use Committee. Twenty-eight urethane-anesthetized male zebra finches (Taeniopygia guttata) of three different ages were used: (1) $43-47 \mathrm{~d}$ posthatch (dph; mean, $45.5 ; n=6$ ); (2) 54-68 dph (mean, 60.9; $n=10$ ); and (3) adult birds ( $>90 \mathrm{dph} ; n=12$ ). All birds were bred in group aviaries and remained with their natural parents until at least $35 \mathrm{dph}$ to ensure that they received normal tutor song exposure and social experience (Immelmann, 1969; Böhner, 1983, 1990; Eales, 1985; Clayton, 1987; Catchpole and Slater, 1995; Mann and Slater, 1995; Roper and Zann, 2006). Because birds were raised by their parents, they were exposed to their father's song (the tutor song) during both the early period of social imprinting as well as during the tutor memorization period; although the presence of the tutor during the imprinting period does not affect song learning (Roper and Zann, 2006), exposure to the tutor song during imprinting might influence the development of neural responsiveness.

Previous work in our laboratory has shown, consistent with the studies cited above, that natural rearing until $35 \mathrm{dph}$ constitutes sufficient tutor exposure to develop an accurate copy of the tutor song (Foster and Bottjer, 2001). Most birds raised under these naturalistic conditions (i.e., by their biological parents within a colony) memorize the song of their father (see references above). Because juveniles had access to other adult males, they could have memorized some aspects of other males' songs (Williams, 1990). However, this tendency would result in weaker tuning to the tutor song of the natural father and would therefore work against an overall pattern of tutor tuning. Therefore, the tutor for each bird was its natural father; because the songs of individual zebra finches vary considerably, each experimental bird learned a specific and unique tutor song (TUT).

Song stimuli. Birds were placed in individual sound attenuation chambers, and songs were recorded using Sound Analysis Pro ( $44 \mathrm{kHz}$ sampling rate; Tchernichovski et al., 2000). All song stimuli were chosen based on how frequently they were produced by each bird, as in previous studies (Solis and Doupe, 1999; Phan et al., 2006; Kojima and Doupe, 2007); at least 10 song bouts (periods in which multiple song motifs are sung) for adult song and at least 20 song bouts for juvenile song were inspected both aurally and visually to pick the song motif that represented the most frequently produced song for each bird. Each song stimulus was high-pass filtered at $400 \mathrm{~Hz}$ and edited to include one or two song motifs (Solis and Doupe, 1997; Rosen and Mooney, 2000; Solis and Doupe, 2000). Because juvenile song is variable, at the onset of each recording session, we tested several (four to five) motifs of each juvenile bird's own song (BOS) that were produced within $24 \mathrm{~h}$ before the experiment. Each version of BOS elicited similar responses in $\mathrm{LMAN}_{\text {core }}$ and LMAN $_{\text {shell }}$ of all birds tested (Solis and Doupe, 1997, 1999, 2000); we chose the version of BOS that produced the largest neural response and used it thereafter. This song was also played back as a mirror-image reverse (REV). Conspecific songs (CON) were recorded from adult breeders from nonadjacent aviaries. Age-matched conspecific songs (AMC) were recorded from unfamiliar juveniles matched to age $\pm 1 \mathrm{~d}$ of the experimental bird. Although previous studies have found no intensity preferences in song control nuclei (Margoliash and Fortune, 1992; Doupe, 1997), we equalized song stimuli to $68.6 \pm 0.3 \mathrm{~dB}$ (mean $\pm \mathrm{SEM})$ measured with a sound level meter (Extech Instruments). Twenty iterations of each stimulus were presented. Song stimuli were presented in blocks of three to five different stimuli (depending on how many stimuli were presented for a given bird). The order of stimuli within a block was random (without replacement), and the interstimulus interval was $10 \pm 2 \mathrm{~s}$.

Electrophysiology. One to $2 \mathrm{~d}$ before an experiment, birds were anesthetized with $1.5 \%$ isoflurane (inhalation), and a stainless steel post was attached to the skull with dental cement. On the day of the experiment, birds were anesthetized with an intramuscular injection of $20 \%$ urethane in $\mathrm{dH}_{2} \mathrm{O}(100-110 \mu \mathrm{l}$; Sigma), and the steel post was fixed to a stereotaxic apparatus so that the ears were unobstructed during recording. Extracellular recordings were made using single electrodes (0.4-0.8 M $\Omega$; Carbostar) or linear electrode 16-pad arrays (1.5-5 M $\Omega$; NeuroNexus). Spike data was amplified (Neuralynx), band passed between 300 and $5000 \mathrm{~Hz}$, and digitized at 20 or $32 \mathrm{kHz}$ using Spike 2 software (Cambridge Electronic Design). Small electrolytic lesions $(4-7 \mu \mathrm{A}$ for $20 \mathrm{~s})$ were made above and below $\mathrm{LMAN}_{\text {core }}$ for single electrodes and in the bottom-most and top-most recording pads of linear arrays for electrode tract reconstruction. Coronal sections ( $50 \mu \mathrm{m}$ thick) were Nissl stained to reveal LMAN $_{\text {core }}$ borders, and, for seven birds, an alternate series was stained for calbindin using standard immunohistochemical procedures to con-

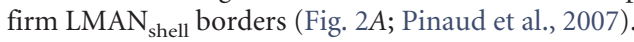


A
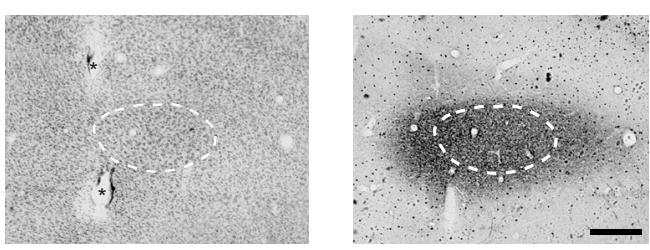

B

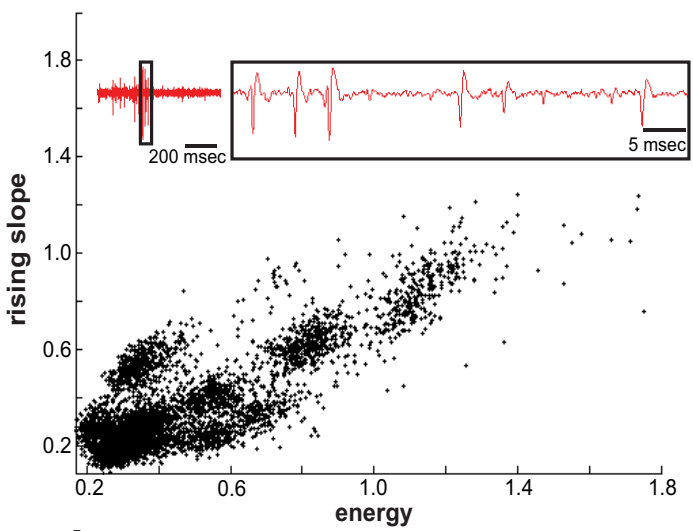

C

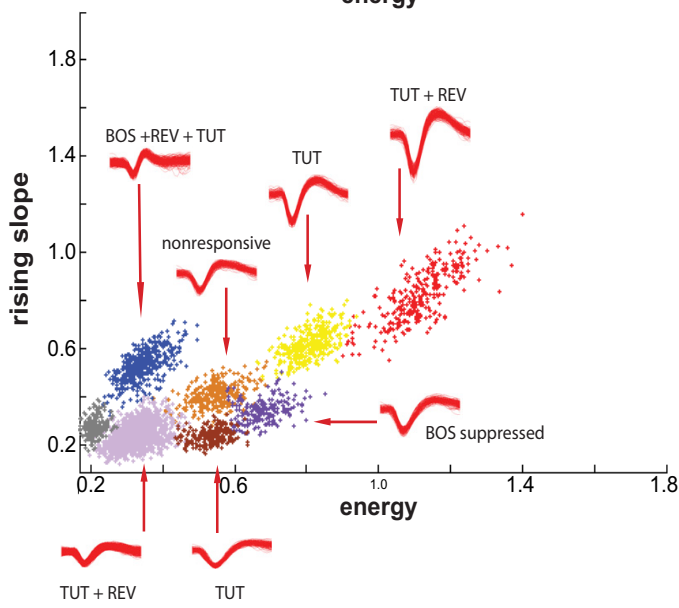

Figure 2. Histological and electrophysiological methods used. $A$, Photomicrograph of LMAN core and shell (50- $\mu \mathrm{m}$-thick coronal sections; medial is right). The borders of the core region can be clearly distinguished in Nissl-stained tissue (left). Core is outlined with dashed line and asterisks indicate fiduciary lesions. Different subgroups of thalamic projection neurons (from DLM; Fig. 1A) terminate in either LMAN core $_{\text {or }}$ LMAN $_{\text {shell, }}$, but all DLM axons express calbindin in a highly selective manner (Pinaud et al., 2007). Therefore, calbindin staining encompasses both core and shell regions, and the terminal field demarcates the outer border of $\mathrm{LMAN}_{\text {shell }}$ (right, dark staining; dashed line is copy of core outline to illustrate location of core). Scale bar, $300 \mu \mathrm{m} . \boldsymbol{B}, \boldsymbol{C}$, Example multiunit recording with clustered spike waveforms from $\mathrm{LMAN}_{\text {shell }}$ of $43 \mathrm{dph}$ bird. $\boldsymbol{B}$, Inset at top left shows raw voltage signal of multiunit recording made with a Carbostar electrode; black box indicates expanded portion shown to right. LMAN neurons have relatively low firing rates, and therefore ambivalent waveform shapes attributable to overlapping spikes were rare. The graph shows a plot of energy versus rising slope of raw waveforms (no corrections applied) from the recording site shown in inset. This plot shows that raw spike shapes form distinct clusters even when based on only two features. C, Waveforms were automatically clustered based on six waveform features using KlustaKwik (Ken Harris, Rutgers University; see Materials and Methods). The resulting clusters for this recording are shown in different colors (gray cluster did not meet signal/noise criterion); overlaid waveforms of each unit are shown near the plotted cluster. After clustering, each unit was tested to determine whether the firing rate during the presentation of any stimulus was significantly greater or less than the firing rate during baseline; each unit is labeled with its corresponding response pattern.

Analyses. A recording site was considered for analysis if it was confirmed histologically to be in either $\mathrm{LMAN}_{\text {core }}$ or LMAN shell $_{\text {(excluding }}$ $50 \mu \mathrm{m}$ on either side of the core/shell border). The evoked responses of LMAN neurons tended not to persist throughout the whole stimulus, as has been observed previously (Doupe, 1997; Solis and Doupe, 1997,
1999; Kojima and Doupe, 2007). Therefore, response strengths calculated for song stimuli longer than $\sim 1 \mathrm{~s}$ underestimated the actual response by averaging across both the early phasic response and the period of decreased response (cf. Doupe, 1997; Solis and Doupe, 1999). To correct for stimulus duration bias (e.g., longer songs would yield speciously low response strengths), all analyses were performed using neural data collected during the first second of song playback (if the song was $>1 \mathrm{~s}$; some adult songs were slightly $<1 \mathrm{~s}$ in duration). Our results for LMAN $_{\text {core }}$ replicate those reported previously (Doupe, 1997; Solis and Doupe, 1997, 2000; Rosen and Mooney, 2000; Kojima and Doupe, 2007), showing that calculation of response strength based on the first second did not change the nature of the results. In addition, because neurons showed either an enhanced or a suppressed response to song playback (see Results), it was important to determine whether rate increases and rate decreases were evaluated equally when restricting the analysis to the first second of the response. To address this point quantitatively, we examined the time course of responses of 20 randomly selected neurons that showed decreased firing rates during playback. Decreases in firing rate in this sample of neurons lasted on average $0.13-1.20 \mathrm{~s}$ after stimulus onset. This pattern was equivalent to that of neurons that show increases in firing rate; that is, like rate increases, rate decreases occurred primarily during the first second of a song stimulus. We also assessed the responses of 20 randomly selected neurons that showed no significant change in firing rate during playback to test whether any of these neurons showed a significant increase or decrease in firing rate if the response window was extended to the entire stimulus length. None of these neurons showed any significant responses when tested this way. Therefore, restriction of analyses to the first second does not differentially reject neurons that show decreased firing rates, and extending the analysis window did not increase the incidence of song-responsive neurons.

Isolated units were clustered manually using MClust-3.5 (A. David Redish, University of Minnesota, Minneapolis, MN; Fig. $2 B, C$ ) in MATLAB (MathWorks). To confirm the quality of clustering, all $45 \mathrm{dph}$ recordings were reclustered automatically using KlustaKwik (Ken Harris, Rutgers University, Newark, NJ) based on the maximum and first derivative of energy of the waveforms, the first two principal components, and the rising and falling slope of the waveforms. Within KlustaKwik, the minimum and maximum number of clusters required was 4 and 30, respectively, and the KlustKwik clustering algorithm was used. Those clusters were then manually inspected and corrected when needed. The two different sorting methods yielded highly similar patterns of data; the results presented here are from the $45 \mathrm{dph}$ data that were automatically clustered. Spike sorting methods inevitably include some error (Harris et al., 2000; Pedreira et al., 2012), but standard precautions were taken to ensure that any error was minimal: single units were considered for analysis if the signal-to-noise ratio was $\geq 3$ (mean \pm SEM, $5.9 \pm 0.09$ ) and if $<1 \%$ of spikes had an interspike interval $<2 \mathrm{~ms}$ (core: $45 \mathrm{dph}, n=93,60$ dph, $n=214$; adult, $n=308$; shell: $45 \mathrm{dph}, n=114 ; 60 \mathrm{dph}, n=172$; adult, $n=265$ ).

We determined whether each single unit was responsive by testing for a significant change in firing rate from baseline ( $1 \mathrm{~s}$ before stimulus) during presentation of any song stimulus (matched $t$ test, $p<0.05$ ). To compare differences in firing rates across neurons, standardized responses (SRs) were calculated:

standardized

$$
\text { response strength }=\frac{\bar{S}-\bar{B}}{\sqrt{\operatorname{Var}(S)+\operatorname{Var}(B)-2 \times \operatorname{Covar}(S, B)}},
$$

where $S$ is firing rate during stimulus, and $B$ is firing rate during baseline so that a positive value indicates an increased rate to a stimulus and a negative value indicates a decreased rate to a stimulus. We did not adjust the SRs for the number of trials (i.e., multiply SR by $\sqrt{ } \#$ trials). Therefore, when accounting for the number of trials, all neurons that were considered responsive to a stimulus showed an adjusted SR of at least 2.24. In describing the responses of single units, use of the word "only" signifies that an individual neuron gave a statistically significant response to only one stimulus of three to five tested (see Results). For example, 


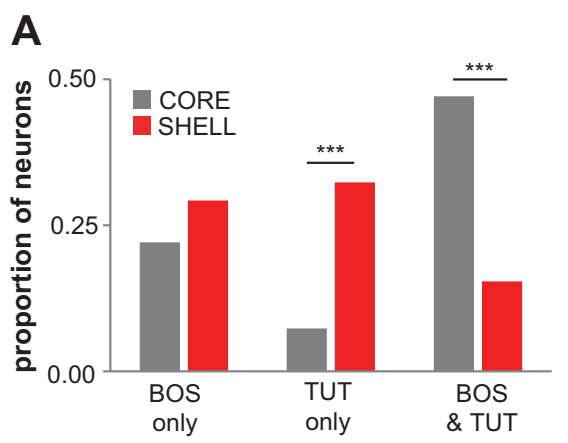

B

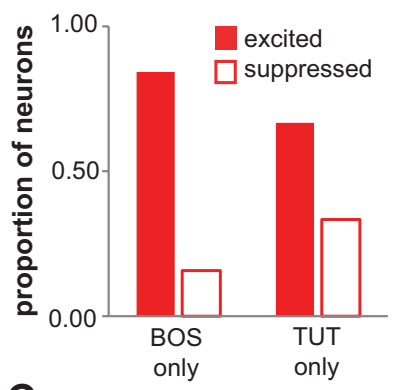

C

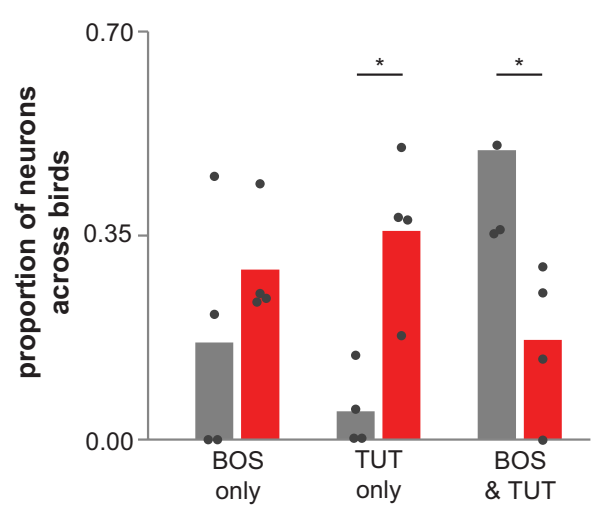

Figure 3. A population of neurons in $\mathrm{LMAN}_{\text {shell }}$ of $45 \mathrm{dph}$ birds responds only to tutor song. $A$, Among all neurons that were tested with playback of BOS, REV, and TUT: absolute proportions of neurons that responded to BOS only, TUT only, or both BOS and TUT in LMAN $n=68$ ) and $\operatorname{LMAN}_{\text {shell }}$ (red; $n=65$ ). For this analysis, "BOS only" included neurons that showed a significant response to BOS and not to REV or TUT (see Materials and Methods), "TUT only" included neurons that responded only to TUT and not to BOS or REV, and "BOS \& TUT" includes neurons that responded to both BOS and TUT (regardless of whether there was a response to REV). Shell neurons in all three response categories include cells that showed either rate increases or decreases (see Results); analysis conducted on only excited neurons yielded highly similar results (data not shown). ${ }^{* *} p \leq 0.001$. $\boldsymbol{B}$, Among all shell neurons included in $\boldsymbol{A}$, proportions of neurons that were either excited (filled bars) or suppressed (open bars) by BOS only or TUT only. $C$, Among all neurons included in $A$, mean proportion of neurons averaged across each bird that responded to BOS only, TUT only, or both stimuli in LMAN LMAN $_{\text {shell }}$ (red). Data from individual birds are plotted as dots ( $n=4$ birds; not included are data from one bird that did not receive the TUT stimulus and from one bird from which we recorded one BOS/TUT-responsive neuron). The mean proportion of TUT-only neurons per bird was higher in shell than in core ( $p=0.019$, Mann-Whitney test), and the mean proportion of BOS \& TUT neurons per bird was higher in core than in shell ( $p=0.021$, Mann-Whitney test). ${ }^{*} p<0.05$. These data show that the differences between core and shell computed across individual birds were also significant and match those computed across neurons.

"TUT only" refers to neurons that gave a significant response only to TUT and not to any other stimulus. In contrast, "TUT-responsive" neurons included those that showed a significant response to TUT, regardless of whether they also responded significantly to other stimuli. Similarly, "BOS only" refers to the subset of neurons that responded significantly only to BOS and not to any other stimulus, and "BOS re-
Table 1. Proportion of auditory neurons in $45 \mathrm{dph}$ core and shell, which were tested with all five stimuli (BOS, REV, TUT, CON, and AMC)

\begin{tabular}{llll}
\hline Row & Neuron category & $\begin{array}{l}\text { Core } \\
(n=52)\end{array}$ & $\begin{array}{l}\text { Shell } \\
(n=40)\end{array}$ \\
\hline 1 & TUT only & 0.04 & $0.28^{* *}$ \\
2 & TUT + REV, CON or AMC & 0.10 & 0.05 \\
3 & BOS + TUT only & 0.08 & 0.05 \\
4 & BOS + TUT + other songs & 0.25 & $0.05^{*}$ \\
5 & BOS only & 0.15 & 0.13 \\
6 & BOS + REV, CON or AMC & 0.25 & 0.20 \\
Sum 2-4/sum & Relative percentage of TUT-responsive neurons & 91 & $35^{* * *}$ \\
$\quad$ 1-4 & that respond to other songs & & \\
Sum 3,4,6/sum & Relative percentage of BOS-responsive neurons & 79 & 70 \\
3-6 & that respond to other songs & & \\
\hline
\end{tabular}

For this analysis, "TUT only" indicates neurons that showed a significant response to TUT and not to BOS, REV, CON or AMC; "BOS only" indicates neurons that responded significantly to BOS and not to REV, TUT, CON, or AMC. Rows $1-6$ sum to $87 \%$ for core and $76 \%$ for shell (remaining neurons did not respond to BOS or TUT). ${ }^{*} p<0.05{ }^{* *} p<$ 0.01 , and ${ }^{* * *} p<0.001$ for significant differences between $\operatorname{LMAN}_{\text {core }}$ and $\operatorname{LMAN}_{\text {shell }}$ proportions ( $\chi^{2}$ tests).

sponsive" refers to the larger group of neurons that responded significantly to BOS regardless of responses to other song stimuli. When describing the responses of single units, "excited" and "suppressed" are used as operational terms that signify firing rate increases and decreases compared with baseline rates and are not descriptions of the underlying synaptic mechanisms responsible for changes in firing rate.

To measure selectivity, a difference score was calculated for "Song A" as follows: Song $\mathrm{A}_{\Delta \mathrm{SR}}=\mathrm{SR}_{\text {Song } \mathrm{A}}-\mathrm{SR}_{\text {Song } \mathrm{B}}$. This is an alternative to the psychometric discriminability index $d^{\prime}$ used in previous studies. We chose to standardize responses before subtracting as opposed to subtracting response strengths and dividing by the standard deviations as in $d^{\prime}$. As other groups have noted (Solis and Doupe, 1997; Coleman and Mooney, 2004), this use of $d^{\prime}$ scores has limitations, including the fact that the score is sensitive to response strength and is less useful for revealing the degree to which the response of one stimulus is greater or less than another. Selectivity scores based on proportions were not appropriate for the data because there were frequently negative response strengths that would confound the interpretation of the score. Use of SR differences corrects for differences in response strength, allows the interpretation of scores calculated from a negative response, and retains one of the benefits of $d^{\prime}$, insensitivity to sample size. To address whether $d^{\prime}$ scores would produce substantially different patterns of selectivity, we calculated $d^{\prime}$ values for 45 dph TUT- and BOS-responsive neurons (see Tables 2, 3). Comparison of $d^{\prime}$ scores with $\Delta$ SR scores revealed no substantial differences. As shown for $\Delta$ SR scores, $d^{\prime}$ values revealed that neurons in shell were more selective for BOS or TUT than core neurons. To include all song-responsive neurons in selectivity measures, regardless of whether cells showed increased or decreased firing rates, we reversed the $\Delta$ SR scores and $d^{\prime}$ values of song-suppressed neurons.

Statistics. All continuous data were tested for normality using Kolmogorov-Smirnov and Shapiro-Wilk tests. $t$ tests were used to compare means for normally distributed data, and Mann-Whitney tests were used to compare medians for non-normally distributed data. Differences in proportions were tested using $\chi^{2}$ tests, and differences in distributions were tested with Kolmogorov-Smirnov $Z$ tests. A $Z$ test for proportions was used to test whether the relative proportions of excited and suppressed 45 dph shell neurons were different from chance. Bonferroni's corrections were applied wherever multiple comparisons were made.

\section{Results}

Distinct neuronal populations in $\mathrm{LMAN}_{\text {core }}$ and $\mathrm{LMAN}_{\text {shell }}$ of juvenile birds

To test whether LMAN $_{\text {shell }}$ contains a neural representation of the tutor song during vocal learning, we recorded from core and shell regions of LMAN in juvenile zebra finches (Taeniopygia guttata) that have completed memorization of a tutor song and begun to practice their song vocalizations ( $45 \mathrm{dph}$ ). We tested each neuron for auditory responsiveness, expressed as a significant change in 
A
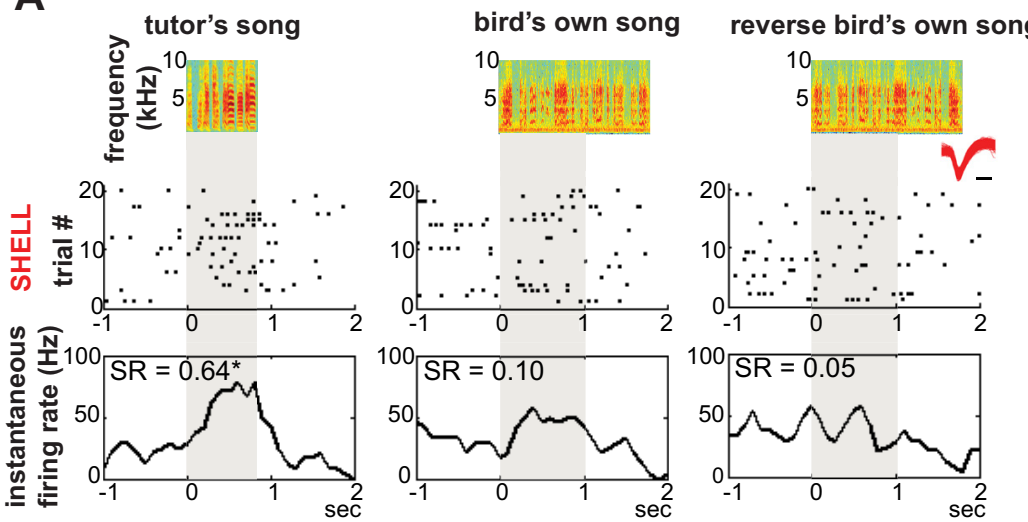

B
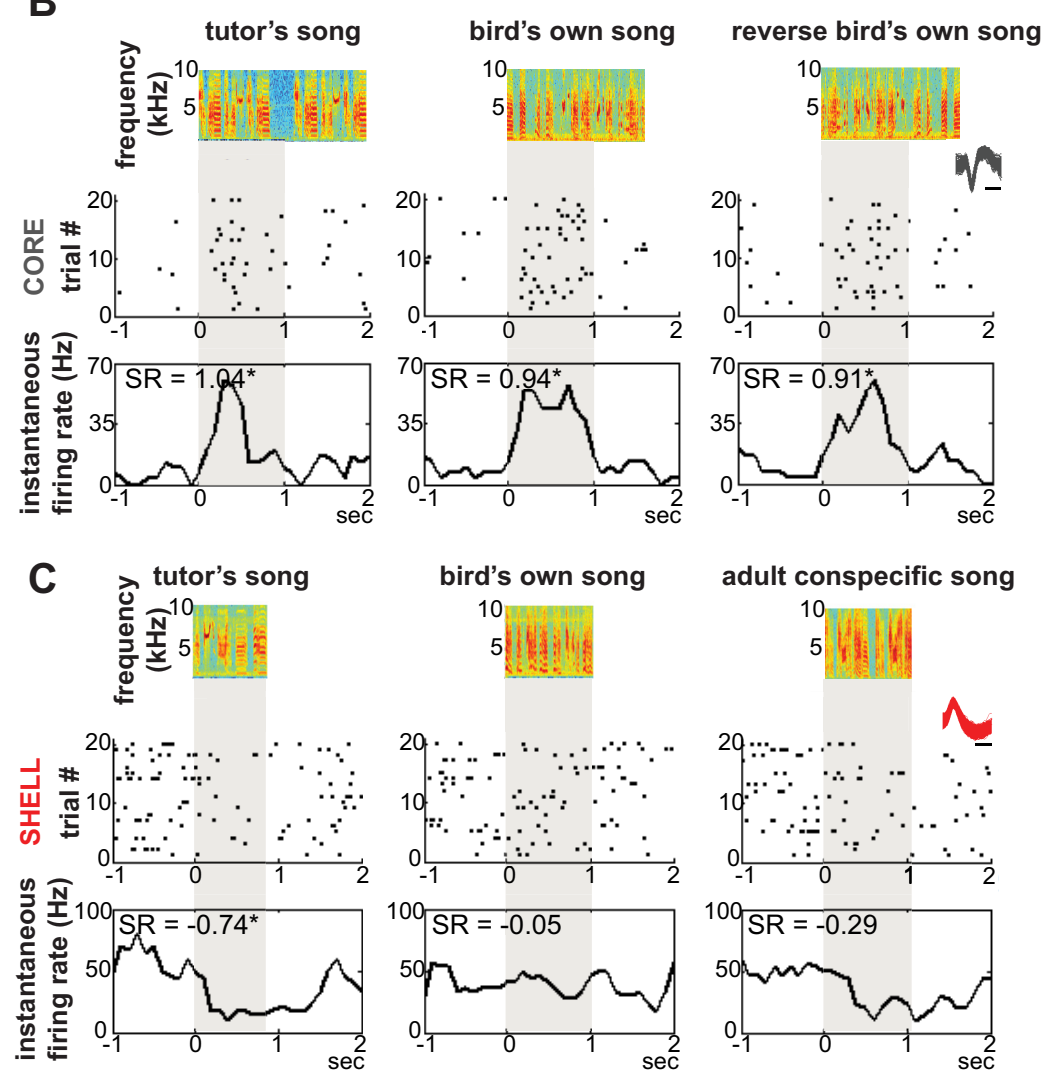

Figure 4. Neurons responsive to the tutor song in $45 \mathrm{dph} \mathrm{LMAN}_{\text {shell }}$ and $\mathrm{LMAN}_{\text {core }}$. $\boldsymbol{A}$, Recording from $\mathrm{LMAN}_{\text {shell }}$. Top, Song spectrograms of a $45 \mathrm{dph}$ bird's TUT, BOS, and REV. Below are raster plots and instantaneous firing rates for a TUT-excited single unit; overlaid waveforms are shown in inset (see Materials and Methods and Fig. 2 B, (for recording and spike sorting details). Scale bar, $0.5 \mathrm{~ms}$. * indicates response significantly different from baseline activity. $\boldsymbol{B}$, Recording from $\mathrm{LMAN}_{\text {core }}$ of $43 \mathrm{dph}$ bird, arranged as in $\boldsymbol{A}$ showing responses to TUT, BOS, and REV. $\boldsymbol{C}$, Recording from LMAN $_{\text {shell }}$ of $45 \mathrm{dph}$ bird showing a TUT-suppressed single unit, arranged as in $\boldsymbol{A}$ and $\boldsymbol{B}$ showing responses to TUT, BOS, and AMC.

firing rate from baseline during playback of each song stimulus $(p<0.05, t$ test $)$. A high proportion of neurons in both core and shell gave an auditory response to playback of at least one song stimulus; the proportion of core neurons that showed a significant auditory response was higher than that for shell neurons ( 0.89 vs $0.68, p<0.001, \chi^{2}$ test; core, $n=83$ of 93 ; shell, $n=77$ of 114; core/shell auditory neurons per birds for $n=6$ birds, $n=$ $18 / 17,0 / 16,20 / 36,2 / 0,32 / 4$, and 11/4).

As an initial population analysis, we categorized each auditory neuron according to whether it exhibited a significant change in firing rate to BOS only, TUT only, or both BOS and TUT (Fig. $3 A$; all of these neurons were tested with TUT, BOS, and a mirror-image reverse of BOS in which temporal structure is reversed while leaving spectral content intact). For example, TUT-only neurons showed a statistically significant response only to TUT and not to BOS or REV (see Materials and Methods). A large proportion of neurons in shell showed a significant response only to TUT $(0.32,21$ of 65 neurons). In contrast, only a small proportion of core neurons responded to TUT only $\left(0.07,5\right.$ of 68 neurons; $p=0.003, \chi^{2}$ test $)$. However, approximately equal proportions of core and shell neurons responded only to BOS. In addition, a large proportion of core neurons responded to both BOS and TUT, whereas few shell neurons responded significantly to both stimuli ( 0.47 vs $0.15 ; 32$ of 68 vs 10 of 65 neurons; $p<0.0001, \chi^{2}$ test). These results show that $\mathrm{LMAN}_{\text {shell }}$ contains two distinct populations of auditory neurons during the period of sensorimotor integration: those that respond only to the tutor song and a separate population that responds only to the current version of the bird's own song. Relatively few shell neurons respond to both BOS and TUT. In contrast, the majority of neurons in $\mathrm{LMAN}_{\text {core }}$ respond either only to the bird's own song or to both BOS and TUT.

To more fully characterize the populations of core and shell neurons, we presented a subset of neurons with an expanded stimulus set of five different songs, including an adult CON and AMC in addition to BOS, REV, and TUT (Table 1). Despite the inclusion of more song types, these data confirmed that a large proportion of neurons gave a significant response only to the tutor song in $\mathrm{LMAN}_{\text {shell }}$ compared with a smaller proportion in $\mathrm{LMAN}_{\text {core }}$ ( 0.28 vs $0.04,11$ of 40 vs 2 of 52 neurons; $p<0.01, \chi^{2}$ test). A relatively large proportion of core neurons responded significantly to combinations of TUT plus other songs compared with shell neurons (sum of rows $2-4 ; 0.43$ vs 0.15 ; $p=0.005, \chi^{2}$ test). Expressed as a relative percentage, $91 \%$ of individual TUTresponsive neurons in core also responded to other songs compared with only $35 \%$ in shell $\left(p<0.001, \chi^{2}\right.$ test). The proportion of neurons that responded only to BOS did not differ between core and shell ( 0.15 vs $0.13,8$ of 52 vs 5 of 40 neurons), confirming that each subregion contains a population of neurons that responds only to BOS (compare with Fig. $3 A$ ). Fewer shell than core neurons were BOSresponsive overall (sum of rows $3-6 ; 0.73$ vs $0.43 ; p=0.003$, $\chi^{2}$ test), such that, although more neurons in core than shell responded to BOS plus other stimuli (sum of rows 3, 4, and 6; 0.58 vs $0.30 ; p=0.008, \chi^{2}$ test), the relative percentage of BOS-responsive neurons that also responded to other songs 
did not differ between core and shell (79 vs $70 \%)$. Interestingly however, many neurons in core were very broadly tuned (i.e., responded significantly to BOS, TUT, plus at least one other song stimulus; row 4) compared with shell (0.25 vs $0.05 ; 13$ of 52 vs 2 of 40 neurons).

Figure 4 shows examples of individual TUT-responsive neurons in $45 \mathrm{dph}$ juvenile $\mathrm{LMAN}_{\text {shell }}$ and $\mathrm{LMAN}_{\text {core }}$ during playback of various song stimuli. Rasters for each neuron indicate that responses in both subregions tended to be somewhat sparse and variable from trial to trial, as reported previously for $\mathrm{LMAN}_{\text {core }}$ (Doupe, 1997). A representative TUTresponsive $\mathrm{LMAN}_{\text {shell }}$ neuron showed a strong response only to TUT, as well as a modest but nonsignificant response to BOS and an even lower response to BOS played in reverse (Fig. 4A). In contrast, a typical TUT-responsive neuron from LMAN $_{\text {core }}$ gave a significant increased rate to BOS, REV, and TUT (Fig. 4B). This broad responsiveness concurs with previous studies that found that most TUTresponsive neurons in core also respond to BOS (Solis and Doupe, 1997; 1999; 2000; Yazaki-Sugiyama and Mooney, 2004), as was also true for TUT-responsive neurons found in other song-control nuclei (Nick and Konishi, 2005a). Another difference between shell and core subregions was that song-evoked activity in shell neurons could manifest as either increases or decreases in firing rate, whereas core neurons showed increased rate responses only. Figure $4 C$ shows a shell neuron that showed a suppressed response to TUT but not to BOS or CON (see below).

Figure 5 shows examples of individual BOS-responsive neurons in shell and core of $45 \mathrm{dph}$ juveniles. The core neuron fired strongly in response to BOS, REV, and TUT, whereas the shell neuron showed significant increased firing only to BOS. Thus, as for TUT-responsive neurons, BOS-responsive neurons in core tended to respond to multiple other stimuli, whereas those in shell were likely to respond strongly only to BOS. In this example, the response of the shell neuron distinguished the bird's own babbling song from that of another young bird (AMC) as well as from the tutor song.

\section{Neurons in $\mathrm{LMAN}_{\text {shell }}$ of 45 dph birds were either excited or suppressed by playback}

As indicated above, many auditory neurons in shell, but not core, of $45 \mathrm{dph}$ birds showed suppressed responses to playback of song (Fig. 4C). Among all BOS-responsive shell neurons (i.e., those that showed a significant response to BOS alone or in combination with other song stimuli), 81\% (29 of 36) were excited, whereas 19\% (7 of 36) showed a suppressed response to BOS. Among TUT-responsive shell neurons, 76\% (28 of 37) showed excitation and 24\% (9 of 37) showed suppression to TUT. Interestingly, BOS- and TUT-excited shell neurons never showed suppression to any other stimulus. This mutual exclusion was true for suppressed neurons as well (except for 1 of 73 cases in which the neuron showed increased firing to REV and suppression to TUT). Thus, shell neurons encoded a representation of TUT and BOS via either increases or decreases in response strength.

Among core neurons that were tested with TUT, BOS, and $\mathrm{REV}$, none showed suppression to any song $(n=68)$. In contrast, among shell neurons that responded only to BOS, 84\% (16 of 19) showed an enhanced response, whereas $16 \%$ (3 of 19) showed a suppressed response ( $p=0.003, Z$ test for proportion; Fig. $3 B$ ). Among shell neurons that responded only to TUT, 67\% (14 of 21 ) showed increased firing and 33\% (7 of 21) showed suppression ( $p=0.12, Z$ test for proportion). This pattern suggests that neurons that responded only to TUT were more likely to show suppression than were neurons that responded only to BOS in LMAN $_{\text {shell }}$ of $45 \mathrm{dph}$ birds. However, despite the tendency toward a greater incidence of song suppression within neurons that responded only to TUT, the relative proportion of excited/suppressed neurons was not significantly different between neurons that responded only to TUT and those that responded only to $\operatorname{BOS}\left(p=0.20, \chi^{2}\right.$ test $)$.

\section{TUT-responsive neurons were more selectively tuned in} juvenile shell than core

To test the relative magnitude of responses across all TUTresponsive neurons, we compared response strengths with all song stimuli in $45 \mathrm{dph}^{\mathrm{LMAN}}$ shell and $\mathrm{LMAN}_{\text {core }}$. SRs for TUTexcited shell neurons were largest to TUT compared with all 
A

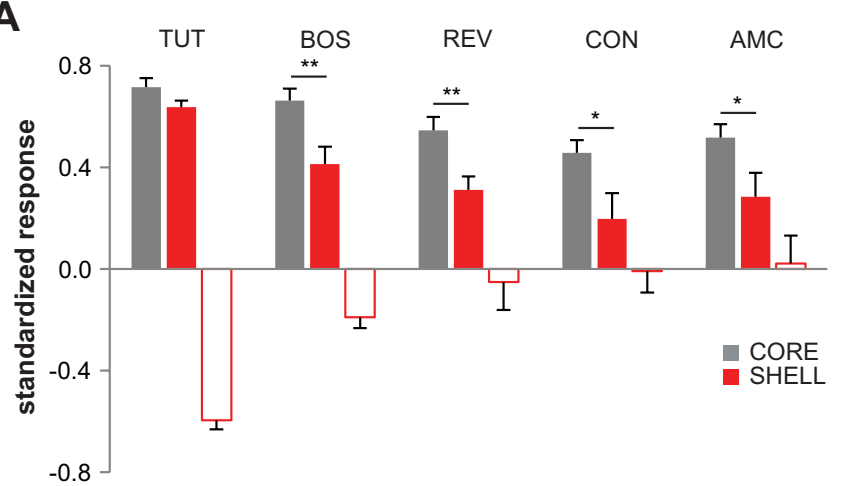

$\mathbf{E}$

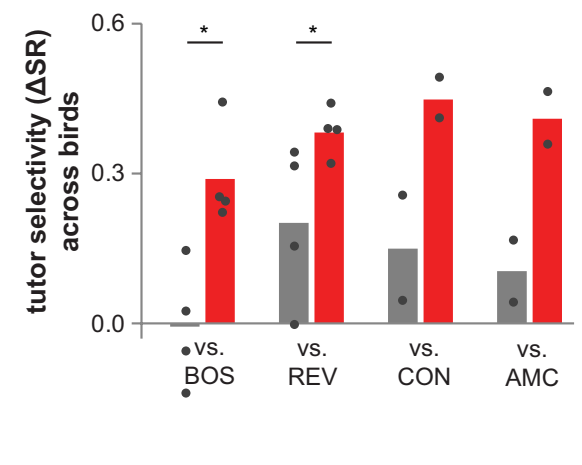

B
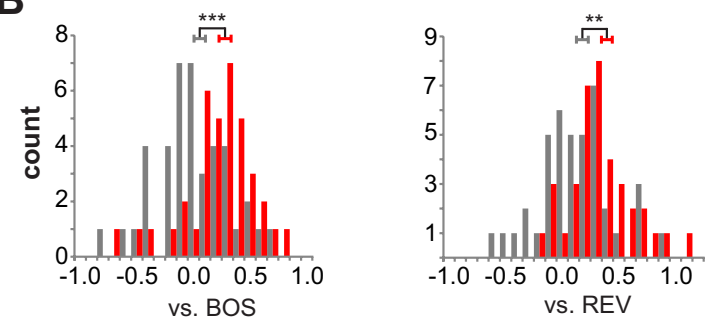

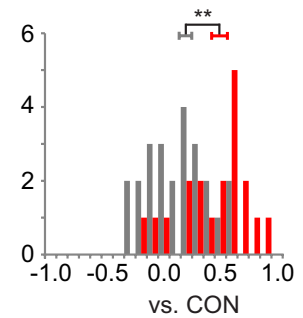

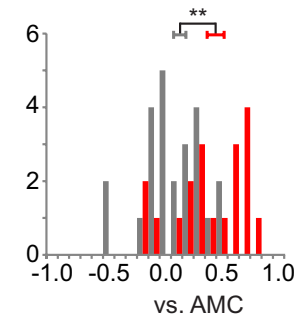

tutor selectivity $(\Delta \mathrm{SR})$

\section{C}

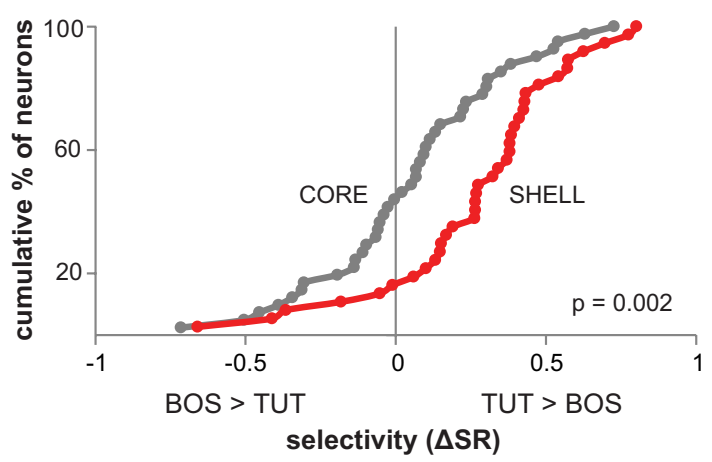

D

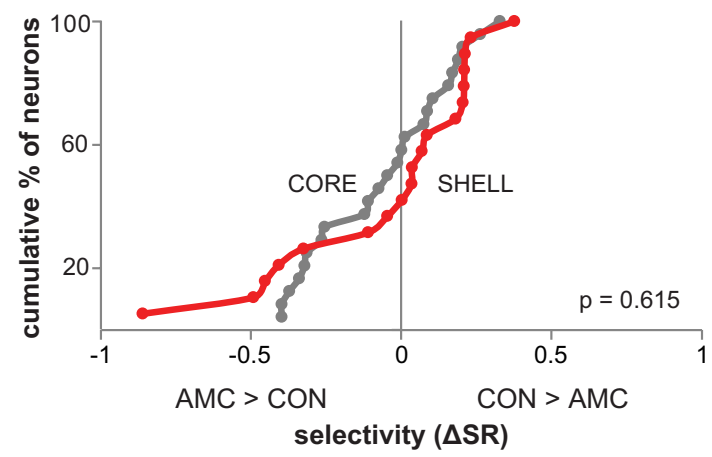

Figure 6. Response strength and selectivity across all TUT-responsive neurons in $\mathrm{LMAN}_{\text {shell }}$ and $\mathrm{LMAN}_{\text {core }}$ of $45 \mathrm{dph}$ birds. TUT-responsive neurons include all those that showed a significant response to TUT (either alone or in combination with other song stimuli, includes both TUT-excited and TUT-suppressed neurons). $A$, SRs for TUT-responsive neurons in core and shell to TUT, BOS, REV, adult CON, and AMC. Filled bars show mean response of neurons that were excited by TUT (core, $n=41$ for TUT, BOS, and REV and $n=24$ for CON and AMC; shell, $n=28$ for TUT, BOS, and REV and $n=12$ for CON and AMC), and open bars show mean response of neurons that were suppressed by TUT (core, $n=0$; shell, $n=9$ for TUT, BOS, and REV and $n=7$ for CON and AMC). Error bars indicate SEM. ${ }^{*} p<0.05,{ }^{* *} p<0.01$, and ${ }^{* * *} p<0.001$. $\boldsymbol{B}$, Histograms showing distributions of selectivity ( $\Delta$ SR) scores for TUT versus other songs (excited and suppressed responses combined) in core and shell (core, $n=41$ vs BOS and REV, $n=24$ vs CON and AMC; shell, $n=37$ vs BOS and REV, $n=19$ vs CON and AMC). The sign of selectivity scores for suppressed neurons is reversed. Error bars are centered on mean values and indicate SEM. C, $\boldsymbol{D}$, Cumulative distributions of TUT-BOS $\Delta$ SR scores (core, $n=41$; shell, $n=37$ ) and of CON-AMC $\Delta$ SRscores (core, $n=24$; shell, $n=19$ ); $p$ values shown are from Kolmogorov-Smirnov Z tests for difference between the distributions. $\boldsymbol{E}$, TUT selectivity averaged across birds to compare with means averaged across neurons ( $\boldsymbol{B}$ ). Bars show mean selectivity for TUT over other songs across birds in core (gray) and shell (red). Data for individual birds are plotted as dots. Mean selectivity scores per bird were higher in shell than in core for comparisons with both BOS and REV ( $p=0.02$ and 0.04 , respectively, Mann-Whitney test; $n=5$ birds vs BOS and vs REV, one bird had recordings only in core and one bird had recordings only in shell; not included are data from one bird that did not receive the TUT stimulus; $n=2$ birds vs (ON and vs AMC). These data show that mean values do not differ, regardless of whether values are computed based on means of individual birds or across all neurons.

other songs (Fig. 6 A, filled red bars; $p<0.05$ in all cases, independent $t$ test, unequal variance, Bonferroni's corrected). In contrast, TUT-excited core neurons responded equally well to TUT and BOS (filled gray bars; $p=1.0$, Mann-Whitney test, Bonferroni's corrected) but, like shell neurons, responded less to REV, CON, and AMC $(p<0.05$ in all cases, Mann-Whitney test, Bonferroni's corrected). Furthermore, shell neurons responded much less to BOS, REV, CON, and AMC than did those in core $(p<0.05$ in all cases, independent $t$ test, unequal variance for CON comparison). Neurons in shell that exhibited suppression to TUT showed similar response patterns to TUT-excited neurons: response suppression was greatest to TUT compared with other songs (open red bars; $p<0.01$ in all cases, Mann-Whitney test, Bonferroni's corrected). As indicated above, TUT-suppressed neurons were not detected in core. In summary, TUT-responsive neurons in core and shell showed comparable response strength to TUT, but neurons in shell gave a much weaker response to non-tutor songs than did those in core.

To quantify response selectivity between pairs of stimuli, we computed a difference score for each neuron: $\Delta \mathrm{SR}=\mathrm{SR}_{\text {Song A }}-$ 
Table 2. $d^{\prime}$ values (mean \pm SEM) for $45 \mathrm{dph}$ core and shell for TUT-responsive neurons

\begin{tabular}{lll}
\hline & \multicolumn{2}{l}{ TUT-responsive 45 dph neurons } \\
\cline { 2 - 3 }$d^{\prime}$ comparison & Core & Shell \\
\hline TUT-BOS & $0.00 \pm 0.06$ & $0.26 \pm 0.07^{* *}$ \\
TUT-REV & $0.26 \pm 0.07$ & $0.48 \pm 0.07^{*}$ \\
TUT-CON & $0.23 \pm 0.09$ & $0.63 \pm 0.12^{* *}$ \\
TUT-AMC & $0.16 \pm 0.08$ & $0.54 \pm 0.12^{* *}$ \\
\hline
\end{tabular}

Core, $n=41$ versus $\mathrm{BOS}$ and $\mathrm{REV}, n=24$ versus CON and AMC; shell, $n=37$ versus BOS and REV, $n=19$ versus CON and AMC. ${ }^{*} p<0.05$ and ${ }^{* *} p<0.01$ for significant differences between mean $d^{\prime}$ values of core and shell. We used $\Delta S R$ scores in preference to $d^{\prime}$ scores for methodological reasons (see Materials and Methods). However, both measures showed good agreement in terms of assessing differences in selectivity between shell and core neurons: TUT selectivity of shell neurons was higher than that in core neurons.

$\mathrm{SR}_{\text {Song B }}$ (a score of zero indicates no song preference). Across all TUT-responsive neurons in shell of $45 \mathrm{dph}$ birds, mean selectivity $(\Delta \mathrm{SR})$ scores revealed a significant preference for TUT versus all other songs (Fig. $6 B ; \Delta$ SR significantly different from zero, $p<$ 0.001 in all cases, one-sample $t$ test; Fig. $6 E$ shows data for individual birds; for $d^{\prime}$ scores, see Table 2). Neurons in core also preferred TUT over REV, CON, and AMC (all cases significantly different from zero, $p<0.05$, one-sample $t$ test). However, there was no significant selectivity for TUT versus BOS $(p=0.30$, one-sample $t$ test), indicating no song preference between TUT and BOS in $45 \mathrm{dph}$ core neurons. Furthermore, shell neurons exhibited much greater selectivity for TUT over all other songs than did core neurons ( $p$ value always $<0.005$, independent $t$ test). These results for TUT-responsive neurons demonstrate that shell neurons showed greater selectivity for TUT compared with those in core for all comparisons with other song stimuli.

Cumulative distributions of selectivity scores for TUT versus BOS were shifted to the right for shell relative to core neurons (Fig. 6C), demonstrating that more neurons preferred TUT over BOS in shell $(p=0.002$, Kolmogorov-Smirnov $Z$ test $)$. As a control for whether the selective response to TUT simply reflected a preference for an adult song versus an immature juvenile song, we also compared cumulative distributions for adult CON versus AMC (Fig. 6D). Shell neurons evinced no preference for CON over AMC ( $p=0.56$, one-sample $t$ test $)$, and the distributions of core versus shell selectivity scores did not differ $(p=0.62$, Kolmogorov-Smirnov $Z$ test). Thus, TUT-responsive shell neurons show a specific preference for the tutor song they have memorized as opposed to a generic preference for general characteristics of adult song over immature song.

\section{BOS-responsive neurons were more selectively tuned in juvenile shell than core}

We also tested BOS-responsive neurons in shell versus core of 45 $\mathrm{dph}$ birds by comparing relative response strength across song stimuli. BOS-excited neurons in both core and shell showed a stronger response to BOS than to all other songs (Fig. 7A; $p<$ 0.01 for all cases, Mann-Whitney test, Bonferroni's corrected). However, shell neurons responded less strongly to REV, TUT, and AMC than did core neurons $(p=0.005,0.002$, and 0.047, respectively, Mann-Whitney test for REV comparison, independent $t$ test for TUT and AMC comparisons). The response to CON did not differ between core and shell ( $p=0.38$, independent $t$ test, unequal variance). BOS-suppressed neurons were found only in shell and showed greater suppression to BOS compared with REV ( $p=0.002$, Mann-Whitney test, Bonferroni's corrected). Thus, neurons in core and shell responded comparably with the bird's own babbling sounds, but with the exception of CON, neurons in shell gave a much weaker response to nonBOS songs than did those in core.

As in the case of TUT-responsive neurons, higher selectivity scores among BOS-responsive shell neurons reflected their weaker response to non-preferred songs (Fig. 7B). BOSresponsive neurons in both core and shell were selective for BOS over all other songs $(\Delta \mathrm{SR}$ different from zero, $p<0.001$ in all cases, one-sample $t$ test; Fig. $7 E$ shows data for individual birds; for $d^{\prime}$ scores, see Table 3). However, shell neurons showed higher selectivity than core neurons for BOS compared with all other songs ( $p$ values always $<0.03$, Mann-Whitney test for REV and AMC comparisons, independent $t$ test for TUT and CON comparisons). Likewise, more neurons in shell were selective for BOS over TUT than in core, as illustrated by the right-shifted cumulative distribution ( $p=0.009$, Kolmogorov-Smirnov $Z$ test; Fig. $7 C$ ). If BOS-responsive shell neurons simply preferred a juvenile song over adult songs, then one would expect high selectivity scores for AMC-CON comparisons. However, the cumulative distributions of AMC-CON $\Delta$ SR scores revealed no selectivity (Fig. 7D; scores not different from zero; core, $p=0.15$ and shell, $p=0.86$, one sample $t$ test), and there was no difference between the distributions ( $p=0.277$, Kolmogorov-Smirnov $Z$ test). These results show that, although response strength to BOS is similar in core versus shell, responses of shell neurons are more selective as a result of diminished responses to other song stimuli. Therefore, $\mathrm{LMAN}_{\text {shell }}$ of $45 \mathrm{dph}$ birds contains a population of neurons that encodes a selective representation of vocal babbling sounds and a distinct population of neurons that is selective to the adult tutor song of each bird.

\section{Selective tuning to tutor song is restricted to a phase of early sensorimotor integration}

The presence of a substantial population of neurons that respond only to the tutor song in $\mathrm{LMAN}_{\text {shell }}$ of $45 \mathrm{dph}$ birds shows that the shell pathway has access to a representation of target vocal sounds during the period of active imitative learning. To test whether a representation of the tutor song persists in shell neurons after the conclusion of vocal learning, we recorded from core and shell in older juveniles at a later stage of sensorimotor integration when birds are singing "plastic" song (60 dph) and in adults that are producing a stereotyped song after the learning period ( $>90 \mathrm{dph}$ ). These neurons were categorized as in Figure 3 according to whether BOS, TUT, or both songs evoked a significant response. This developmental analysis revealed that the high proportion of shell neurons showing a significant response only to TUT at $45 \mathrm{dph}$ was greatly reduced by 60 $\mathrm{dph}\left(p=0.01, \chi^{2}\right.$ test, Bonferroni's corrected), and this proportion remained low in adult birds (Fig. $8 A$, left). The substantial reduction of TUT-only shell neurons by $60 \mathrm{~d}$ eliminated the significantly greater incidence of tutor-tuned neurons in shell versus core seen at $45 \mathrm{dph}$. The proportion of core neurons that responded only to TUT did not change between 45 and $60 \mathrm{~d}\left(p=0.52, \chi^{2}\right.$ test, Bonferroni's corrected).

Developmental changes in BOS responses showed a different pattern (Fig. 8A, middle). The proportion of neurons that showed a significant response only to BOS increased in both core and shell between 45 and $60 \mathrm{~d}$ (core, $p=0.03$ and shell, $p=0.07$, $\chi^{2}$ test, Bonferroni's corrected) and was not different between the two subregions at any age. Therefore, the neural representation of each bird's own song became stronger in both subregions of LMAN as vocal development progressed from vocal babbling to plastic song. The proportion of core neurons that responded to both BOS and TUT decreased substantially between 45 and $60 \mathrm{~d}$ (Fig. $8 A$, right; $p=0.002, \chi^{2}$ test, Bonferroni's corrected) and 

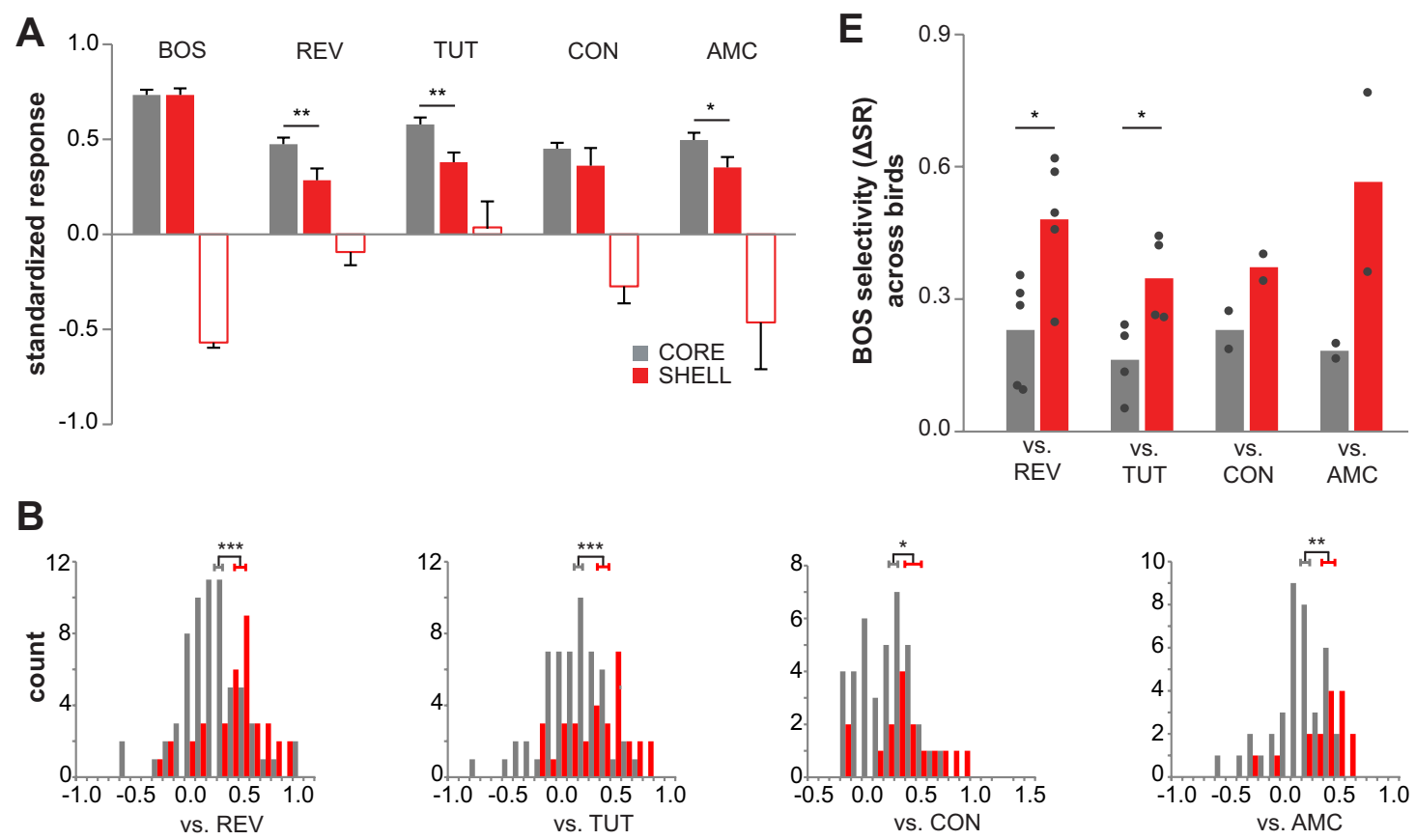

bird's own song selectivity $(\Delta S R)$

C

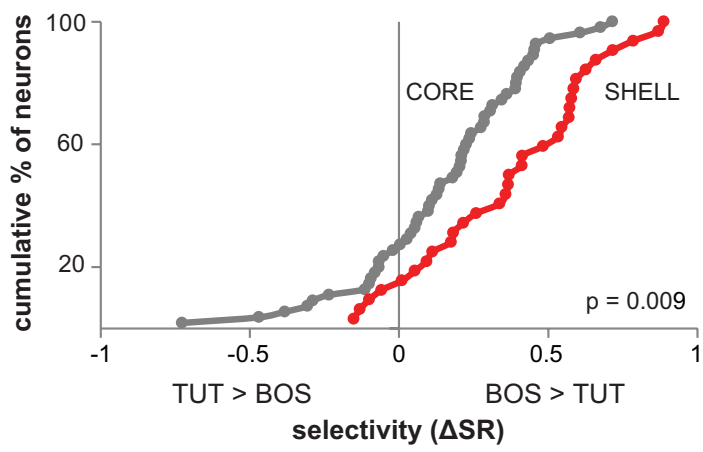

D

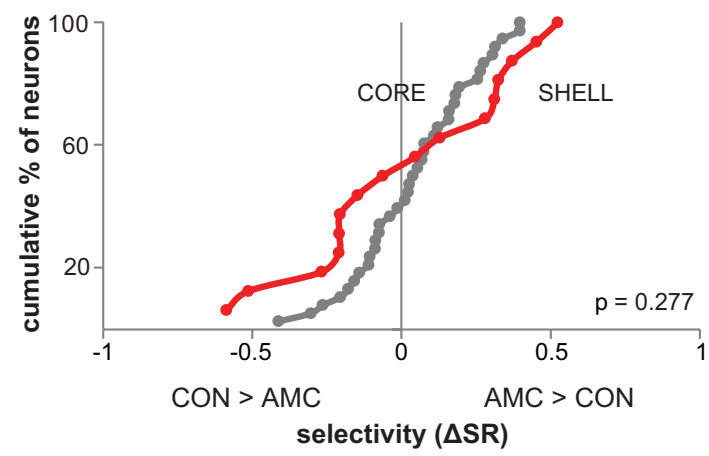

Figure 7. Response strength and selectivity across all BOS-responsive neurons in $\mathrm{LMAN}_{\text {shell }}$ and LMAN $\mathrm{Lore}_{\text {of }} 45 \mathrm{dph}$ birds. $A$, SRs for BOS-responsive neurons in core and shell to BOS, REV, TUT, adult CON, and AMC. Filled bars show mean response of neurons that were excited by BOS (core, $n=65$ for BOS and REV, $n=55$ for TUT, $n=38$ for CON and AMC; shell, $n=29$ for BOS, REV, and TUT, $n=14$ for CON and AMC), and open bars show mean response of neurons that were suppressed by BOS (core, $n=0$; shell, $n=7$ for BOS and REV, $n=3$ for TUT, $n=2$ for CON and AMC). Error bars indicate SEM. ${ }^{*} p<0.05,{ }^{* *} p<0.01$, and ${ }^{* * *} p<0.001$. B. Histograms showing distributions of selectivity ( $\triangle S R$ ) scores for BOS over other songs (excited and suppressed responses combined) in core and shell (core, $n=65$ vs REV, $n=55$ vs TUT, $n=38$ vs CON and AMC; shell, $n=36$ vs REV, $n=32$ vs TUT, $n=16$ vs CON and AMC). The sign of selectivity scores for suppressed neurons is reversed. Error bars are centered on mean values and indicate SEM. C, $\boldsymbol{D}$, Cumulative distributions of BOS-TUT $\triangle$ SR scores (core, $n=55$; shell, $n=32$ ) and AMC-CON $\Delta$ SR scores (core, $n=38$; shell, $n=16$ ). $p$ values shown are from Kolmogorov-Smirnov $Z$ tests for difference between the distributions. $\boldsymbol{E}$, BOS selectivity averaged across birds to compare with means averaged across neurons $(\boldsymbol{B})$. Bars show mean selectivity for BOS over other songs across birds in core (gray) and shell (red). Data for individual birds are plotted as dots. Mean selectivity scores per bird were higher in shell than in core for comparisons with both REV and TUT ( $p=0.047$ and 0.020 , respectively, Mann-Whitney test; $n=6$ birds vs REV, one bird had recordings only in core and one bird had recordings only in shell; $n=5$ birds vs TUT, not included are data from one bird that did not receive the TUT stimulus; $n=2$ birds vs (ON and vs AMC). These data show that mean values do not differ, regardless of whether values are computed based on means of individual birds or across all neurons.

Table 3. $d^{\prime}$ values (mean $\pm \mathrm{SEM}$ ) for $45 \mathrm{dph}$ core and shell for BOS-responsive neurons

\begin{tabular}{lll}
\hline \multirow{2}{*}{$d^{\prime}$ comparison } & \multicolumn{2}{l}{ BOS-responsive 45 dph neurons } \\
\cline { 2 - 3 } & Core & Shell \\
\hline BOS-REV & $0.41 \pm 0.05$ & $0.58 \pm 0.06^{*}$ \\
BOS-TUT & $0.27 \pm 0.04$ & $0.49 \pm 0.07^{* *}$ \\
BOS-CON & $0.39 \pm 0.06$ & $0.62 \pm 0.10^{*}$ \\
BOS-AMC & $0.32 \pm 0.05$ & $0.50 \pm 0.08$ \\
\hline
\end{tabular}

Core, $n=65$ versus REV,$n=55$ versus TUT, $n=38$ versus CON and AMC; shell, $n=36$ versus REV,$n=32$ versus TUT, $n=16$ versus CON and AMC. ${ }^{*} p<0.05$ and ${ }^{* *} p<0.01$ for significant differences between mean $d^{\prime}$ values of core and shell. We used $\Delta S R$ scores in preference to $d^{\prime}$ scores for methodological reasons (see Materials and Methods). However, both measures showed good agreement in terms of assessing differences in selectivity between shell and core neurons: BOS-selectivity of shell neurons was higher than that in core neurons. remained low in adulthood. Although the proportion of shell neurons that responded to both BOS and TUT did not change throughout development, by adulthood a greater proportion of neurons in shell responded to BOS and TUT than in core ( $p=$ $0.008, \chi^{2}$ test, Bonferroni's corrected). In summary, these data show that, with learning, a larger proportion of neurons in both subregions respond significantly only to BOS as song matures, and the proportion of neurons in $\mathrm{LMAN}_{\text {shell }}$ that respond only to the tutor song diminishes.

We found that core neurons became more selectively tuned to BOS during development, in accord with reports of selectivity in previous studies (although this represents the first test of BOS 

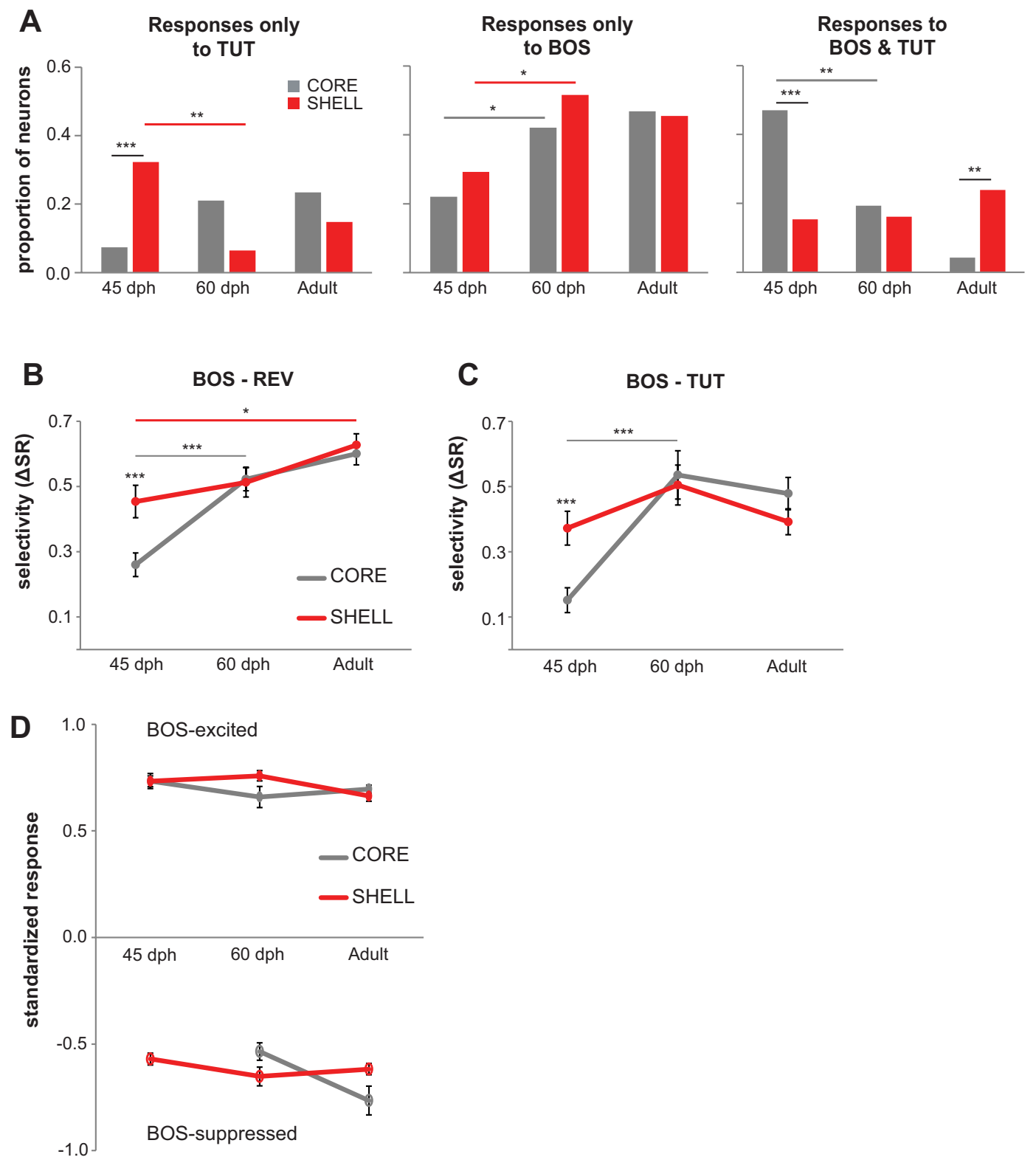

Figure 8. Developmental changes in responses and selective tuning of $\mathrm{LMAN}_{\text {core }}$ and $\mathrm{LMAN}_{\text {shell }}$ neurons. $A$, Proportion of neurons that responded only to TUT and not to BOS or REV (left) in core (gray) and shell (red) at $45 \mathrm{dph}$ (core, $n=68$; shell, $n=65$ ), $60 \mathrm{dph}$ (core, $n=57$; shell, $n=31$ ) and in adult birds (core, $n=47$; shell, $n=88$ ). Proportion of neurons that responded only to B0S and not REV or TUT (middle) and proportion of neurons that responded to both BOS and TUT (right). ${ }^{*} p<0.05$, ${ }^{* *} p<0.01$, and ${ }^{* * *} p<0.001$. The data for 45 dph are the same as those presented in Figure 3. B, Mean BOS-REV $\triangle$ SR scores for BOS-responsive neurons in LMAN $_{\text {core }}$ and LMAN shell $_{\text {in }} 45 \mathrm{dph}$ (core, $n=65$; shell, $n=36$ ), $60 \mathrm{dph}$ (core, $n=53$; shell, $n=26$ ), and adult (core, $n=$ 82; shell, $n=100$ ) birds. Error bars indicate SEM. C, Mean BOS-TUT $\triangle$ SR scores for BOS-responsive neurons in LMAN core $_{\text {and LMAN }}$ shell in 45 dph (core, $n=55$; shell, $n=32$ ), $60 \mathrm{dph}$ (core, $n=$ 40; shell, $n=23$ ), and adult (core, $n=26$; shell, $n=64$ ) birds. D, Mean response strength of all BOS-responsive neurons to BOS across development. Filled circles show mean SRs of BOS-excited neurons in core (gray) and shell (red) to BOS in $45 \mathrm{dph}$ (core, $n=65$; shell, $n=29$ ), $60 \mathrm{dph}$ (core, $n=49$; shell, $n=21$ ), and adult (core, $n=72$; shell, $n=88$ ) birds. Open circles show mean SRs of BOS-suppressed neurons throughout development in core ( $n=0$ at $45 \mathrm{dph}, n=4$ at $60 \mathrm{dph}, n=10$ in adults) and shell ( $n=7$ at $45 \mathrm{dph}, n=5$ at $60 \mathrm{dph}, n=12$ in adults). There were no significant age differences within either subregion for both BOS-excited and BOS-suppressed neurons ( $p>0.05$ in all cases). Error bars indicate SEM.

selectivity in birds younger than $55 \mathrm{dph}$ ) (Doupe, 1997; Solis and Doupe, 1997). The selectivity of core neurons for BOS increased between 45 and $60 \mathrm{dph}(p<0.001$ for both REV and TUT comparisons, independent $t$ test, unequal variance for TUT comparison), such that there was no difference in $\Delta$ SR scores of shell versus core neurons by $60 \mathrm{dph}$ (Fig. $8 B, C$; independent $t$ test, unequal variance for TUT comparison). The selectivity of shell neurons for BOS over both REV and TUT did not change between 45 and $60 \mathrm{dph}$ ( $p>0.05$ in both cases, independent $t$ test, Bonferroni's corrected), although BOS-REV selectivity did increase between $45 \mathrm{dph}$ and adulthood ( $p=0.03$, independent $t$ test, Bonferroni's corrected). Response strength to BOS did not change in either subregion during development (Fig. 8D; MannWhitney test, Bonferroni's corrected), indicating that the developmental increases in BOS selectivity were attributable to decreased responses to other stimuli. These results indicate that shell neurons show relatively more mature levels of selectivity than core neurons early in vocal learning and that the increase in selectivity throughout development in both subregions is the result of weaker responses to nonpreferred stimuli.

Because relative levels of inhibition contribute to neural selectivity (Rosen and Mooney, 2000; 2003; Pinaud et al., 2008) as well 
A

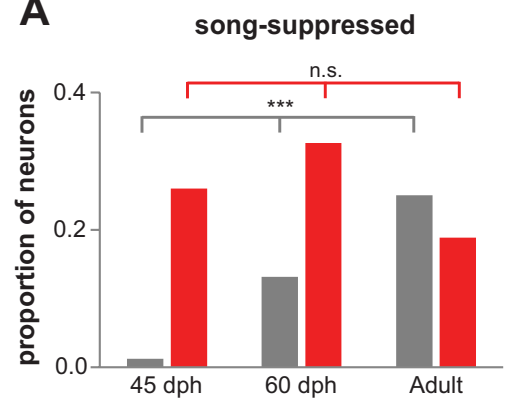

B

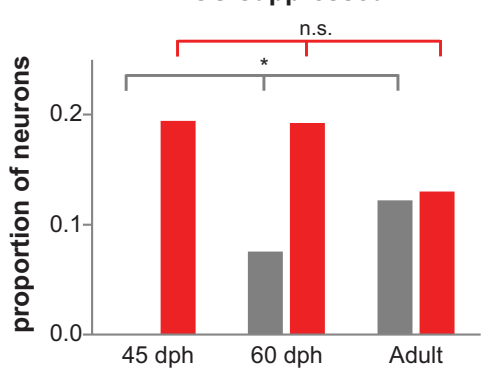

Figure 9. Developmental changes in song-suppressive responses in $\mathrm{LMAN}_{\text {core }}$ and $\mathrm{LMAN}_{\text {shell }}$ neurons. $A$, Proportion of auditory neurons that responded with suppression to any song stimulus in core (gray) and shell (red) at $45 \mathrm{dph}$ (core, $n=83$; shell, $n=77$ ), $60 \mathrm{dph}$ (core, $n=76$; shell, $n=46$ ), and adult (core, $n=120$; shell, $n=154$ ) birds. B, Proportion of BOS-responsive neurons that were suppressed by BOS in core and shell at $45 \mathrm{dph}$ (core, $n=65$; shell, $n=36$ ), $60 \mathrm{dph}$ (core, $n=53$; shell, $n=26$ ), and adult (core, $n=82$; shell, $n=100$ ) birds. $^{*} p<0.05$ and ${ }^{* * *} p<0.001$.

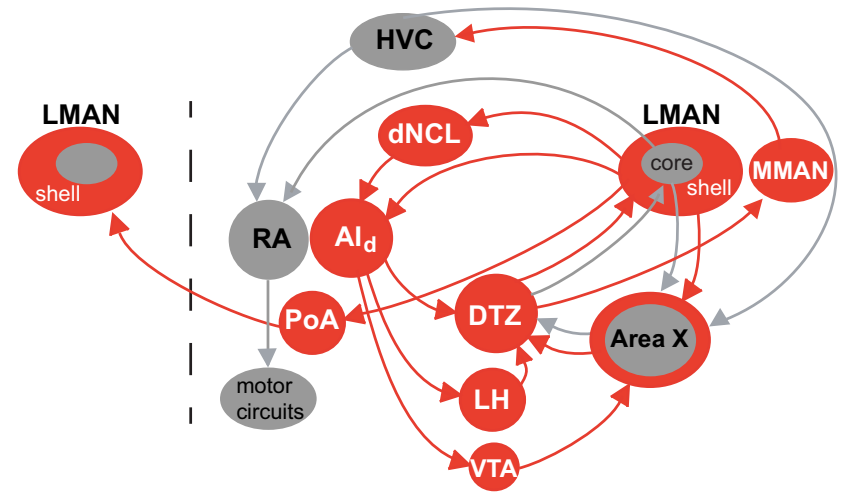

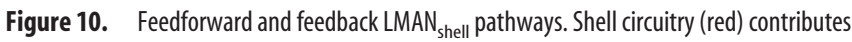
both to feedback pathways through thalamus and through integrative feedforward pathways. One feedforward pathway includes a projection from $\mathrm{Al}_{d}$ (previously referred to as Ad) to dopaminergic neurons in VTA and then to basal ganglia of the core pathway (Area X, gray). Feedforward pathways also project through a dorsal thalamic zone to MMAN and thence to HVC, which controls adult song production through its projection to vocal motor cortex (RA). Main feedback pathways include those discussed in the Results: shell $\rightarrow \mathrm{dNCL} \rightarrow \mathrm{Al}_{\mathrm{d}} \rightarrow \mathrm{DTZ} \rightarrow$ shell and shell $\rightarrow$ Area $X_{\text {shell }} \rightarrow$ DTZ $\rightarrow$ shell. Additional recurrent loops may be made through the projection of $\mathrm{Al}_{\mathrm{d}}$ to VTA and lateral hypothalamus. In addition, $\mathrm{LMAN}_{\text {shell }}$ projects to ipsilateral posterior amygdala, which sends axons to contralateral LMAN shell, $_{\text {, }}$ thereby constituting one pathway that could be used for interhemispheric coordination (Johnson et al., 1995). Posterior pallial amygdala was referred to as Av (ventral arcopallium) in previous papers from our laboratory, but we have changed the terminology here to conform to the nomenclature suggested by Reiner et al. (2004). Dashed line indicates midline. HVC, common name; RA, robust nucleus of arcopallium; $\mathrm{dNCL}$, dorsal caudolateral nidopallium; $\mathrm{Al}_{\mathrm{d}}$, dorsal intermediate arcopallium; LMAN, lateral magnocellular nucleus of the anterior nidopallium; MMAN, medial magnocellular nucleus of the anterior nidopallium; DTZ, dorsal thalamic zone (includes DLM and DMP); Area X, basal ganglia nucleus containing both striatal and pallidal neurons; $\mathrm{LH}$, lateral hypothalamus; VTA, ventral tegmental area; $\mathrm{PoA}$, posterior pallial amygdala.

as regulation of sensitive periods (Hensch et al., 1998), we examined the proportion of all auditory neurons with enhanced versus suppressed responses throughout development. LMAN known to include song-suppressed neurons in adult but not juvenile birds (Doupe, 1997). In accord with this fact, we found that the proportion of core neurons that showed a suppressed response to at least one song stimulus increased throughout development (Fig. $9 A$, gray bars; 0.01 at $45 \mathrm{dph}, 0.13$ at $60 \mathrm{dph}, 0.25$ in adults; $p<0.001$, three-way $\chi^{2}$ test). Among BOS-responsive neurons, the percentage in core that were suppressed by BOS also increased significantly from $0 \%$ at $45 \mathrm{dph}$ to $8 \%$ at $60 \mathrm{dph}$ and $12 \%$ in adults (Fig. $9 B$, gray bars; $p=0.016$, three-way $\chi^{2}$ test). In contrast to core, the proportion of shell neurons that showed

suppression to at least one song stimulus did not change during development (Fig. $9 A$, red bars; 0.26 in 45 dph birds, 0.33 in $60 \mathrm{dph}, 0.18$ in adults; $p=0.12$, three-way $\chi^{2}$ test). Moreover, the percentage of BOS-responsive neurons in shell that were suppressed by BOS did not change during development (Fig. 9B, red bars; $19 \%$ at $45 \mathrm{dph}, 19 \%$ at $60 \mathrm{dph}, 13 \%$ in adults; $p=0.55$, three-way $\chi^{2}$ test). Thus, suppressive responses to song in LMANcore mature throughout development and gradually come to match the level of song suppression seen in $\mathrm{LMAN}_{\text {shell }}$. In addition, these results suggest that maturation of inhibitory circuits may underlie increased selective tuning in LMAN and represent a correlate of learning.

\section{Discussion}

These results demonstrate that $\mathrm{LMAN}_{\text {shell }}$ contains a population of neurons that encodes a neural representation of learned tutor sounds in juvenile songbirds during early stages of sensorimotor integration for vocal learning ( $45 \mathrm{dph}$ ). This discovery represents the first instance in which a substantial population of vocalcontrol neurons responds selectively to tutor song in birds that are acquiring learned vocal behavior. The TUT-tuned neurons are present at a time when lesions of $\mathrm{AI}_{\mathrm{d}}$ (dorsal intermediate arcopallium), which interrupt the trans-cortical recurrent pathway from $\mathrm{LMAN}_{\text {shell }}$ through dorsal thalamus, prevent both imitation of the tutor song and the development of a stable sequence of syllables (Bottjer and Altenau, 2010). Furthermore, the large proportion of neurons that responds only to tutor song is not present in $\mathrm{LMAN}_{\text {shell }}$ of adult birds that have finished learning to produce a stereotyped imitation of that song. Tutor-tuned neurons in 45 dph LMAN ${ }_{\text {shell }}$ coexist with a separate population that responds selectively to the bird's own song, suggesting that discrete populations of shell neurons receive signals from regions of higher-level auditory cortex that process either vocal-related feedback (BOS tuning) or aspects of tutor song (TUT tuning) (Phan et al., 2006; London and Clayton, 2008; Gobes et al., 2010; Hahnloser and Kotowicz, 2010). In contrast to $\mathrm{LMAN}_{\text {shell }}$, most neurons in $\mathrm{LMAN}_{\text {core }}$ of young birds responded to BOS or to BOS plus other songs, in agreement with previous studies (Solis and Doupe, 1999, 2000; Yazaki-Sugiyama and Mooney, 2004). The overall pattern of results indicates that distinct representations of both the tutor song and the bird's own song are available only in shell at $45 \mathrm{dph}$ and that neurons in core do not develop a selective representation of self-produced vocalizations until late in learning.

At $45 \mathrm{dph}, \mathrm{LMAN}_{\text {shell }}$ contained TUT- and BOS-suppressed neurons, demonstrating that shell neurons represent the tutor song and bird's own song via either increases or decreases in firing rate, similar to responses to learned sounds in prefrontal cortex of mammals (Suzuki et al., 1997; Fritz et al., 2010). Thalamic input to LMAN is excitatory (Livingston and Mooney, 1997; Boettiger and Doupe, 1998; Bottjer et al., 1998; Pinaud et al., 2007), so suppression presumably results from intrinsic inhibitory interneurons such as those that contribute to selectivity in core (Rosen and Mooney, 2000). Thus, TUT-tuned and BOStuned excitatory neurons in DLM (dorsolateral medial thalamus) and $\mathrm{LMAN}_{\text {shell }}$ may drive intrinsic inhibitory activity onto specific subgroups of shell neurons (BOS- and TUT-suppressed 
neurons) and contribute to greater selectivity (Blättler and Hahnloser, 2011).

Comparisons of response strength and selectivity across all TUT-responsive neurons showed that individual cells in $45 \mathrm{dph}$ birds were more selectively tuned to TUT in shell than in core. This selectivity was attributable to the fact that shell neurons showed a much weaker response to non-tutor songs than did core neurons. In addition, BOS-responsive core neurons at $45 \mathrm{dph}$ were less selective for BOS than shell neurons. By the time birds reached an intermediate stage of sensorimotor integration $(60$ $\mathrm{dph}$ ), a robust representation of tutor song was no longer present in shell. By this age, BOS-suppressed responses have emerged in core, and core neurons have developed a selective representation of self-produced sounds (Eliades and Wang, 2008). The earlier maturation of selective tuning in $\mathrm{LMAN}_{\text {shell }}$ suggests that shell neurons may contribute to emergent auditory tuning in core neurons between 45 and $60 \mathrm{dph}$.

Sixty days post-hatch corresponds to the earliest time when birds have formed a fairly stable sequence of song syllables and lesions to LMAN (including both core and shell) have lost the ability to substantially disrupt song behavior (Bottjer et al., 1984). Additionally, the volume of LMAN shell $_{\text {increases dramatically }}$ during early sensorimotor integration and regresses by $60 \mathrm{dph}$ (Johnson and Bottjer, 1992; Johnson et al., 1995). Thus, the suite of developmental changes that occurs in LMAN by this age, including the loss of TUT-tuned shell neurons, may reflect a diminished capacity for plasticity and thereby contribute to the close of the sensitive period for vocal learning.

A neural memory of the tutor song represents a necessary target to which feedback of current song behavior can be compared (Thorpe, 1958; Konishi, 1965). Multiple sites are likely to encode a representation of the tutor song (Nick and Konishi, 2005b; London and Clayton, 2008; Prather et al., 2010; Adret et al., 2012), some of which may convey information to LMAN shell $_{\text {. }}$. Another source of tutor song information may come through a postsynaptic target of $\mathrm{LMAN}_{\text {shell }}$, dNCL (dorsal caudolateral nidopallium; Fig. 10), which contributes to the trans-cortical recurrent loop. Indeed, singing in combination with hearing TUT strongly induces immediate early gene expression in dNCL neurons (Bottjer et al., 2010).

The presence of TUT-tuned neurons during a restricted interval of vocal learning suggests that they may serve as a referent that enables a correct imitation of tutor song to gradually emerge during sensorimotor integration. During vocal babbling, juvenile birds will occasionally produce a sound that is similar enough to tutor song to activate TUT-selective neurons; this would enable TUT-tuned neurons to act as a filter for correct performance. Concurrent feedback of babbling sounds could drive BOSselective neurons such that both TUT-tuned and BOS-tuned neurons are activated simultaneously. Convergence of signals from TUT- and BOS-tuned neurons in downstream circuitry would constitute a means of evaluating matches between current and target behavior. Interestingly, the strong transient projection from juvenile core to $\mathrm{AI}_{\mathrm{d}}$ (Miller-Sims and Bottjer, 2012; Fig. 1B) during early stages of song development indicates that shell circuitry receives an efference copy of the motor signal for vocal output. In addition, $\mathrm{AI}_{\mathrm{d}}$ projects to the region of dopaminergic neurons in the ventral tegmental area that projects to Area X (Bottjer et al., 2000) and hence could relay error/reinforcement signals into the cortico-basal ganglia circuits that collectively regulate vocal learning.

Auditory responses are generally reduced during alert wakefulness in the song motor system (Dave et al., 1998; Cardin and
Schmidt, 2004), although BOS-selective responses have been observed in LMAN $_{\text {core }}$ of awake birds (Hessler and Doupe, 1999). Our results were obtained in anesthetized birds, and the role of behavioral state in neural responses of shell neurons is not known. It is possible that, in addition to or instead of an online role, TUT-tuned neurons in $\mathrm{LMAN}_{\text {shell }}$ are important for offline learning that occurs during sleep (Shank and Margoliash, 2009). Chronic recordings in core and shell of juvenile singing birds will be needed to test directly the role of TUT- and BOS-selective neurons.

Models of reinforcement learning in which motor skills are acquired via evaluation of goal-oriented outcomes suggest that parallel basal ganglia circuits like those of $\mathrm{LMAN}_{\text {core }}$ and $\mathrm{LMAN}_{\text {shell }}$ mediate different aspects of learning (Nakahara et al., 2001; Samejima and Doya, 2007). In mammals, neurons in parallel cortico-basal ganglia loops process distinct aspects of rewardbased learning, such as reward prediction error and selected motor actions (Hikosaka et al., 1999; Miyachi et al., 2002; Tanaka et al., 2004; Yin and Knowlton, 2006; Atallah et al., 2007; Samejima and Doya, 2007; Graybiel, 2008; Yin et al., 2009; Thorn et al., 2010; Redgrave et al., 2011). Thorn et al. (2010) describe a model for cortico-basal ganglia circuitry in which sensorimotor pathways regulate motor-related aspects of learning, whereas associative-limbic circuits process goal-directed responses and modulate the sensorimotor loop's control over action. Models based on reinforcement learning have suggested that the LMANcore circuit may function as an "actor/experimenter" to drive variable vocal production (Sutton and Andrew, 1998; Doya and Sejnowski, 2000; Troyer and Doupe, 2000; Fiete et al., 2007; Miller et al., 2010; Fee and Goldberg, 2011). The presence of neurons representing the target behavior-a memory of the tutor song - in juvenile $\mathrm{LMAN}_{\text {shell }}$ is consistent with a model in which shell participates in evaluative goal-oriented responses (Abe and Watanabe, 2011). Like shell neurons, associative cortico-basal ganglia neurons in prefrontal cortex of mammals show activity related to goal states (Saito et al., 2005; Mushiake et al., 2006; Fritz et al., 2010). The $\mathrm{LMAN}_{\text {shell }}$ circuit contributes to both integrative feedforward and feedback pathways, including connections to limbic and reward circuitry (Fig. 10) and so is well suited to integrate these signals with specific song-related information.

The presence and nature of the auditory responses in $\mathrm{LMAN}_{\text {shell }}$, in addition to lesion and anatomical evidence (Johnson and Bottjer, 1992; Johnson et al., 1995; Bottjer and Altenau, 2010; Bottjer et al., 2010; Miller-Sims and Bottjer, 2012), challenge the idea of a single song-control basal ganglia pathway. More generally, these findings show that two distinctly tuned neuronal populations can represent current and target behaviors during learning. Therefore, these results raise the possibility that the division of learning-related functions into parallel corticobasal ganglia loops may be a conserved feature of goal-directed motor learning.

\section{References}

Abe K, Watanabe D (2011) Songbirds possess the spontaneous ability to discriminate syntactic rules. Nat Neurosci 14:1067-1074. CrossRef Medline

Adret P, Meliza CD, Margoliash D (2012) Song tutoring in presinging zebra finch juveniles biases a small population of higher-order song-selective neurons toward the tutor song. J Neurophysiol 108:1977-1987. CrossRef Medline

Aronov D, Andalman AS, Fee MS (2008) A specialized forebrain circuit for vocal babbling in the juvenile songbird. Science 320:630-634. CrossRef Medline

Atallah HE, Lopez-Paniagua D, Rudy JW, O’Reilly RC (2007) Separate neural substrates for skill learning and performance in the ventral and dorsal striatum. Nat Neurosci 10:126-131. CrossRef Medline 
Blättler F, Hahnloser RH (2011) An efficient coding hypothesis links sparsity and selectivity of neural responses. PLoS One 6:e25506. CrossRef Medline

Boettiger CA, Doupe AJ (1998) Intrinsic and thalamic excitatory inputs onto songbird LMAN neurons differ in their pharmacological and temporal properties. J Neurophysiol 79:2615-2628. Medline

Böhner J (1983) Song learning in the zebra finch (Taeniopygia guttata): selectivity in the choice of a tutor and accuracy of song copies. Anim Behav 31:231-237. CrossRef

Böhner J (1990) Early acquisition of song in the zebra finch, Taeniopygia guttata. Anim Behav 39:369-374. CrossRef

Bottjer SW (2004) Developmental regulation of basal ganglia circuitry during the sensitive period for vocal learning in songbirds. Ann N Y Acad Sci 1016:395-415. CrossRef Medline

Bottjer SW, Altenau B (2010) Parallel pathways for vocal learning in basal ganglia. Nat Neurosci 13:153-155. CrossRef Medline

Bottjer SW, Miesner EA, Arnold AP (1984) Forebrain lesions disrupt development but not maintenance of song in passerine birds. Science 224:901903. CrossRef Medline

Bottjer SW, Brady JD, Walsh JP (1998) Intrinsic and synaptic properties of neurons in the vocal-control nucleus IMAN from in vitro slice preparations of juvenile and adult zebra finches. J Neurobiol 37:642-658. CrossRef Medline

Bottjer SW, Brady JD, Cribbs B (2000) Connections of a motor cortical region in zebra finches: relation to pathways for vocal learning. J Comp Neurol 420:244-260. CrossRef Medline

Bottjer SW, Alderete TL, Chang D (2010) Conjunction of vocal production and perception regulates expression of the immediate early gene ZENK in a novel cortical region of songbirds. J Neurophysiol 103:1833-1842. CrossRef Medline

Cardin JA, Schmidt MF (2004) Auditory responses in multiple sensorimotor song system nuclei are co-modulated by behavioral state. J Neurophysiol 91:2148-2163. CrossRef Medline

Catchpole C, Slater PJ (1995) Bird song: biological themes and variations. Cambridge: Cambridge UP.

Clayton NS (1987) Song tutor choice in zebra finches. Anim Behav 35:714721. CrossRef

Coleman MJ, Mooney R (2004) Synaptic transformations underlying highly selective auditory representations of learned birdsong. J Neurosci 24: 7251-7265. CrossRef Medline

Dave AS, Yu AC, Margoliash D (1998) Behavioral state modulation of auditory activity in a vocal motor system. Science 282:2250-2254. CrossRef Medline

Doupe AJ (1997) Song- and order-selective neurons in the songbird anterior forebrain and their emergence during vocal development. J Neurosci 17:1147-1167. Medline

Doupe AJ, Kuhl PK (1999) Birdsong and human speech: common themes and mechanisms. Annu Rev Neurosci 22:567-631. CrossRef Medline

Doya K, Sejnowski TJ (2000) A computational model of avian song learning. In: The new cognitive neurosciences, pp 469-488 Cambridge, MA: Massachusetts Institute of Technology.

Eales LA (1985) Song learning in zebra finches: some effects of song model availability on what is learnt and when. Anim Behav 33:1293-1300. CrossRef

Eliades SJ, Wang X (2008) Neural substrates of vocalization feedback monitoring in primate auditory cortex. Nature 453:1102-1106. CrossRef Medline

Fee MS, Goldberg JH (2011) A hypothesis for basal ganglia-dependent reinforcement learning in the songbird. Neuroscience 198:152-170. CrossRef Medline

Fiete IR, Fee MS, Seung HS (2007) Model of birdsong learning based on gradient estimation by dynamic perturbation of neural conductances. J Neurophysiol 98:2038-2057. Medline

Foster EF, Bottjer SW (2001) Lesions of a telencephalic nucleus in male zebra finches: influences on vocal behavior in juveniles and adults. J Neurobiol 46:142-165. CrossRef Medline

Fritz JB, David SV, Radtke-Schuller S, Yin P, Shamma SA (2010) Adaptive, behaviorally gated, persistent encoding of task-relevant auditory information in ferret frontal cortex. Nat Neurosci 13:1011-1019. CrossRef Medline

Gobes SM, Zandbergen MA, Bolhuis JJ (2010) Memory in the making: lo- calized brain activation related to song learning in young songbirds. Proc Biol Sci 277:3343-3351. CrossRef Medline

Graybiel AM (2008) Habits, rituals and the evaluative brain. Annu Rev Neurosci 31:359-387. CrossRef Medline

Hahnloser RH, Kotowicz A (2010) Auditory representations and memory in birdsong learning. Curr Opin Neurobiol 20:332-339. CrossRef Medline

Harris KD, Henze DA, Csicsvari J, Hirase H, Buzsáki G (2000) Accuracy of tetrode spike separation as determined by simultaneous intracellular and extracellular measurements. J Neurophysiol 84:401-414. Medline

Hensch TK, Fagiolini M, Mataga N, Stryker MP, Baekkeskov S, Kash SF (1998) Local GABA circuit control of experience-dependent plasticity in developing visual cortex. Science 282:1504-1508. CrossRef Medline

Hessler NA, Doupe AJ (1999) Singing-related neural activity in a dorsal forebrain-basal ganglia circuit of adult zebra finches. J Neurosci 19: 10461-10481. Medline

Hikosaka O, Nakahara H, Rand MK, Sakai K, Lu X, Nakamura K, Miyachi S, Doya K (1999) Parallel neural networks for learning sequential procedures. Trends Neurosci 22:464-471. CrossRef Medline

Immelmann K (1969) Song development in the zebra finch and other estrildid finches. In: Bird vocalisations (Hinde RA, ed), pp 61-74. Cambridge, UK: Cambridge UP.

Iyengar S, Viswanathan SS, Bottjer SW (1999) Development of topography within song control circuitry of zebra finches during the sensitive period for song learning. J Neurosci 19:6037-6057. Medline

Johnson F, Bottjer SW (1992) Growth and regression of thalamic efferents in the song-control system of male zebra finches. J Comp Neurol 326: 442-450. CrossRef Medline

Johnson F, Sablan MM, Bottjer SW (1995) Topographic organization of a forebrain pathway involved with vocal learning in zebra finches. J Comp Neurol 358:260-278. CrossRef Medline

Kojima S, Doupe AJ (2007) Song selectivity in the pallial-basal ganglia song circuit of zebra finches raised without tutor song exposure. J Neurophysiol 98:2099-2109. CrossRef Medline

Konishi M (1965) The role of auditory feedback in the control of vocalization in the white crowned sparrow. Zeitschrift fur Tierpsychologie 22: 770-783. Medline

Livingston FS, Mooney R (1997) Development of intrinsic and synaptic properties in a forebrain nucleus essential to avian song learning. J Neurosci 17:8997-9009. Medline

London SE, Clayton DF (2008) Functional identification of sensory mechanisms required for developmental song learning. Nat Neurosci 11:579_ 586. CrossRef Medline

Mann NI, Slater PJ (1995) Song tutor choice by zebra finches in aviaries. Anim Behav 49:811-820. CrossRef

Margoliash D, Fortune ES (1992) Temporal and harmonic combinationsensitive neurons in the zebra finch's HVC. J Neurosci 12:4309-4326. Medline

Marler P (1956) The voice of the Chaffinch and its function as a language. Ibis 98:231-261.

Marler P (1970) A comparative approach to vocal learning: Song development in white-crowned sparrows. J Comp Physiol Psychol 71:1-25. CrossRef

Miller JE, Hilliard AT, White SA (2010) Song practice promotes acute vocal variability at a key stage of sensorimotor learning. PLoS One 5:e8592. CrossRef Medline

Miller-Sims VC, Bottjer SW (2012) Auditory experience refines corticobasal ganglia inputs to motor cortex via re-mapping of single axons during vocal learning in zebra finches. J Neurophysiol 107:1142-1156. CrossRef Medline

Miyachi S, Hikosaka O, Lu X (2002) Differential activation of monkey striatal neurons in the early and late stages of procedural learning. Exp Brain Res 146:122-126. CrossRef Medline

Mushiake H, Saito N, Sakamoto K, Itoyama Y, Tanji J (2006) Activity in the lateral prefrontal cortex reflects multiple steps of future events in action plans. Neuron 50:631-641. CrossRef Medline

Nakahara H, Doya K, Hikosaka O (2001) Parallel cortico-basal ganglia mechanisms for acquisition and execution of visuomotor sequences-a computational approach. J Cogn Neurosci 13:626-647. CrossRef Medline

Nick TA, Konishi M (2005a) Neural auditory selectivity develops in parallel with song. J Neurobiol 62:469-481. CrossRef Medline 
Nick TA, Konishi M (2005b) Neural song preference during vocal learning in the zebra finch depends on age and state. J Neurobiol 62:231-242. CrossRef Medline

O’Doherty J, Dayan P, Schultz J, Deichmann R, Friston K, Dolan RJ (2004) Dissociable roles of ventral and dorsal striatum in instrumental conditioning. Science 304:452-454. CrossRef Medline

Olveczky BP, Andalman AS, Fee MS (2005) Vocal experimentation in the juvenile songbird requires a basal ganglia circuit. PLoS Biol 3:e153. CrossRef Medline

Pedreira C, Martinez J, Ison MJ, Quian Quiroga R (2012) How many neurons can we see with current spike sorting algorithms? J Neurosci Methods 211:58-65. CrossRef Medline

Phan ML, Pytte CL, Vicario DS (2006) Early auditory experience generates long-lasting memories that may subserve vocal learning in songbirds. Proc Natl Acad Sci U S A 103:1088-1093. CrossRef Medline

Pinaud R, Saldanha CJ, Wynne RD, Lovell PV, Mello CV (2007) The excitatory thalamo-"cortical" projection within the song control system of zebra finches is formed by calbindin-expressing neurons. J Comp Neurol 504:601-618. CrossRef Medline

Pinaud R, Terleph TA, Tremere LA, Phan ML, Dagostin AA, Leão RM, Mello CV, Vicario DS (2008) Inhibitory network interactions shape the auditory processing of natural communication signals in the songbird auditory forebrain. J Neurophysiol 100:441-455. CrossRef Medline

Prather JF, Peters S, Nowicki S, Mooney R (2010) Persistent representation of juvenile experience in the adult songbird brain. J Neurosci 30:1058610598. CrossRef Medline

Ravbar P, Lipkind D, Parra LC, Tchernichovski O (2012) Vocal exploration is locally regulated during song learning. J Neurosci 32:3422-3432. CrossRef Medline

Redgrave P, Vautrelle N, Reynolds JN (2011) Functional properties if the basal ganglia's re-entrant loop architecture: selection and reinforcement. Neuroscience 198:138-151. CrossRef Medline

Reiner A, Perkel DJ, Bruce LL, Butler AB, Csillag A, Kuenzel W, Medina L, Paxinos G, Shimizu T, Striedter G, Wild M, Ball GF, Durand S, Güntürkün O, Lee DW, Mello CV, Powers A, White SA, Hough G, Kubikova L, Smulders TV, Wada K, Dugas-Ford J, Husband S, Yamamoto K, Yu J, Siang C, Jarvis ED (2004) Revised nomenclature for avian telencephalon and some related brainstem nuclei. J Comp Neurol 473:377-414. CrossRef Medline

Roper A, Zann R (2006) The onset of song learning and song tutor selection in fledgling zebra finches. Ethology 112:458-470. CrossRef

Rosen MJ, Mooney R (2000) Intrinsic and extrinsic contributions to auditory selectivity in a song nucleus critical for vocal plasticity. J Neurosci 20:5437-5448. Medline

Rosen MJ, Mooney R (2003) Inhibitory and excitatory mechanisms underlying auditory responses to learned vocalizations in the songbird nucleus HVC. Neuron 39:177-194. CrossRef Medline

Saito N, Mushiake H, Sakamoto K, Itoyama Y, Tanji J (2005) Representation of immediate and final behavioral goals in the monkey prefrontal cortex during an instructed delay period. Cereb Cortex 15:1535-1546. CrossRef Medline
Samejima K, Doya K (2007) Multiple representations of belief states and action values in cortico-basal ganglia loops. Ann N Y Acad Sci 1104: 213-228. CrossRef Medline

Scharff C, Nottebohm F (1991) A comparative study of the behavioral deficits following lesions of various parts of the zebra finch song system: implications for vocal learning. J Neurosci 11:2896-2913. Medline

Shank SS, Margoliash D (2009) Sleep and sensorimotor integration during early vocal learning in a songbird. Nature 458:73-77. CrossRef Medline

Solis MM, Doupe AJ (1997) Anterior forebrain neurons develop selectivity by an intermediate stage of birdsong learning. J Neurosci 17:6447-6462. Medline

Solis MM, Doupe AJ (1999) Contributions of tutor and bird's own song experience to neural selectivity in the songbird anterior forebrain. J Neurosci 19:4559-4584. Medline

Solis MM, Doupe AJ (2000) Compromised neural selectivity for song in birds with impaired sensorimotor learning. Neuron 25:109-121. CrossRef Medline

Sutton RSB, Andrew G (1998) Reinforcement learning: an introduction. Cambridge, MA: Massachusetts Institute of Technology.

Suzuki WA, Miller EK, Desimone R (1997) Object and place memory in the macaque entorhinal cortex. J Neurophysiol 78:1062-1081. Medline

Tanaka SC, Doya K, Okada G, Ueda K, Okamoto Y, Yamawaki S (2004) Prediction of immediate and future rewards differentially recruits cortico-basal ganglia loops. Nat Neurosci 7:887-893. CrossRef Medline

Tchernichovski O, Nottebohm F, Ho CE, Pesaran B, Mitra PP (2000) A procedure for an automated measurement of song similarity. Anim Behav 59:1167-1176. CrossRef Medline

Thorn CA, Atallah H, Howe M, Graybiel AM (2010) Differential dynamics of activity changes in dorsolateral and dorsomedial striatal loops during learning. Neuron 66:781-795. CrossRef Medline

Thorpe WH (1958) The learning of song patterns by birds, with especial reference to the song of the Chaffinch Fringilla coelebs. Ibis 100:535-570.

Troyer TW, Doupe AJ (2000) An associational model of birdsong sensorimotor learning. I. Efference copy and the learning of song syllables. J Neurophysiol 1204-1223.

Warren TL, Tumer EC, Charlesworth JD, Brainard MS (2011) Mechanisms and time course of vocal learning and consolidation in the adult songbird. J Neurophysiol 106:1806-1821. CrossRef Medline

Williams H (1990) Models for song learning in the zebra finch: fathers or others? Anim Behav 39:745-757. CrossRef

Yazaki-Sugiyama Y, Mooney R (2004) Sequential learning from multiple tutors and serial retuning of auditory neurons in a brain area important to birdsong learning. J Neurophysiol 92:2771-2788. CrossRef

Yin HH, Knowlton BJ (2006) The role of the basal ganglia in habit formation. Nat Rev Neurosci 7:464-476. CrossRef Medline

Yin HH, Mulcare SP, Hilário MR, Clouse E, Holloway T, Davis MI, Hansson AC, Lovinger DM, Costa RM (2009) Dynamic reorganization of striatal circuits during the acquisition and consolidation of a skill. Nat Neurosci 12:333-341. CrossRef Medline 